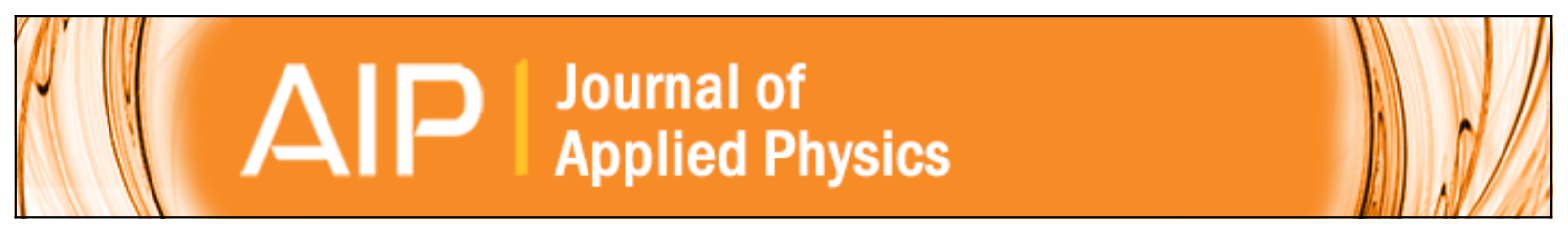

\title{
Extended X-ray absorption fine structure investigation of Sn local environment in strained and relaxed epitaxial Ge1-xSnx films
}

F. Gencarelli, D. Grandjean, Y. Shimura, B. Vincent, D. Banerjee, A. Vantomme, W. Vandervorst, R. Loo, M. Heyns, and K. Temst

Citation: Journal of Applied Physics 117, 095702 (2015); doi: 10.1063/1.4913856

View online: http://dx.doi.org/10.1063/1.4913856

View Table of Contents: http://scitation.aip.org/content/aip/journal/jap/117/9?ver=pdfcov

Published by the AIP Publishing

\section{Articles you may be interested in}

Investigation of Sn surface segregation during GeSn epitaxial growth by Auger electron spectroscopy and energy dispersive $\mathrm{x}$-ray spectroscopy

Appl. Phys. Lett. 106, 052103 (2015); 10.1063/1.4907863

Epitaxial GeSn film formed by solid phase epitaxy and its application to Yb2O3-gated GeSn metal-oxidesemiconductor capacitors with sub-nm equivalent oxide thickness

Appl. Phys. Lett. 105, 203508 (2014); 10.1063/1.4902119

Investigation of the direct band gaps in Ge1-xSnx alloys with strain control by photoreflectance spectroscopy Appl. Phys. Lett. 100, 102109 (2012); 10.1063/1.3692735

Increased photoluminescence of strain-reduced, high-Sn composition Ge1- x Sn x alloys grown by molecular beam epitaxy

Appl. Phys. Lett. 99, 181125 (2011); 10.1063/1.3658632

Structural characterization of the $\mathrm{Co} 2 \mathrm{Fe} \mathrm{Z}$ ( $\mathrm{Z}=\mathrm{Al}, \mathrm{Si}, \mathrm{Ga}$, and $\mathrm{Ge}$ ) Heusler compounds by x-ray diffraction and extended $x$-ray absorption fine structure spectroscopy

Appl. Phys. Lett. 90, 172501 (2007); 10.1063/1.2731314

Frustrated by

old technology?

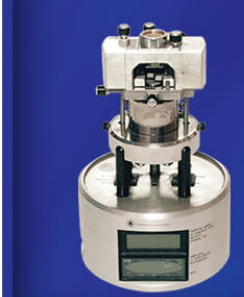

Is your AFM dead

and can't be repaired?

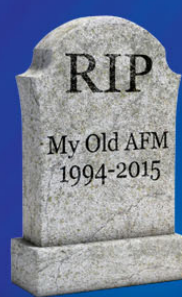

Sick of bad customer support?

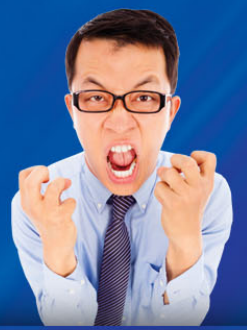

It is time to upgrade your AFM

Minimum $\$ 20,000$ trade-in discount for purchases before August 31st

Asylum Research is today's technology leader in AFM 


\title{
Extended X-ray absorption fine structure investigation of Sn local environment in strained and relaxed epitaxial $\mathrm{Ge}_{1-\mathrm{x}} \mathbf{S n}_{\mathbf{x}}$ films
}

\author{
F. Gencarelli, ${ }^{1,2, a)}$ D. Grandjean, ${ }^{3}$ Y. Shimura,${ }^{1,4, b)}$ B. Vincent, ${ }^{1}$ D. Banerjee, ${ }^{5}$ A. Vantomme,${ }^{4}$ \\ W. Vandervorst, ${ }^{1,4}$ R. Loo, ${ }^{1}$ M. Heyns, ${ }^{1,2}$ and K. Temst ${ }^{4}$ \\ ${ }^{1}$ imec, Kapeldreef 75, 3001 Leuven, Belgium \\ ${ }^{2}$ Department of Metallurgy and Materials Engineering, KU Leuven, Kasteelpark Arenberg 44, B-3001 Leuven, \\ Belgium \\ ${ }^{3}$ Laboratory for Solid State Physics and Magnetism, KU Leuven, Celestijnenlaan 200D, B-3001 Leuven, \\ Belgium \\ ${ }^{4}$ Instituut voor Kern- en Stralingsfysica, KU Leuven, Celestijnenlaan 200D, B-3001 Leuven, Belgium \\ ${ }^{5}$ Dutch-Belgian Beamline (DUBBLE), ESRF - The European Synchrotron, CS 40220, 38043 Grenoble, France
}

(Received 9 October 2014; accepted 18 February 2015; published online 6 March 2015)

\begin{abstract}
We present an extended X-ray absorption fine structure investigation of the local environment of $\mathrm{Sn}$ atoms in strained and relaxed $\mathrm{Ge}_{1-\mathrm{x}} \mathrm{Sn}_{\mathrm{x}}$ layers with different compositions. We show that the preferred configuration for the incorporation of $\mathrm{Sn}$ atoms in these $\mathrm{Ge}_{1-\mathrm{x}} \mathrm{Sn}_{\mathrm{x}}$ layers is that of a $\alpha$-Sn defect, with each Sn atom covalently bonded to four Ge atoms in a classic tetrahedral configuration. Sn interstitials, Sn-split vacancy complexes, or Sn dimers, if present at all, are not expected to involve more than $2.5 \%$ of the total $\mathrm{Sn}$ atoms. This finding, along with a relative increase of $\mathrm{Sn}$ atoms in the second atomic shell around a central $\mathrm{Sn}$ atom in $\mathrm{Ge}_{1-\mathrm{x}} \mathrm{Sn}_{\mathrm{x}}$ layers with increasing $\mathrm{Sn}$ concentrations, suggests that the investigated materials are homogeneous random substitutional alloys. Within the accuracy of the measurements, the degree of strain relaxation of the $\mathrm{Ge}_{1-\mathrm{x}} \mathrm{Sn}_{\mathrm{x}}$ layers does not have a significant impact on the local atomic surrounding of the Sn atoms. Finally, the calculated topological rigidity parameter $\mathrm{a}^{* *}=0.69 \pm 0.29$ indicates that the strain due to alloying in $\mathrm{Ge}_{1-\mathrm{x}} \mathrm{Sn}_{\mathrm{x}}$ is accommodated via bond stretching and bond bending, with a slight predominance of the latter, in agreement with ab initio calculations reported in literature. (C) 2015 AIP Publishing LLC. [http://dx.doi.org/10.1063/1.4913856]
\end{abstract}

\section{INTRODUCTION}

Despite its potential, $\mathrm{Ge}_{1-\mathrm{x}} \mathrm{Sn}_{\mathrm{x}}$ technology is still in its infancy with various unresolved fundamental questions. A better understanding of the local environment of $\mathrm{Sn}$ atoms and its variation with the lattice strain and the alloy composition would give valuable insight into the specific $\mathrm{Ge}_{1-\mathrm{x}} \mathrm{Sn}_{\mathrm{x}}$ growth/relaxation mechanism and it would allow more accurate band structure calculations. In addition, such understanding could indicate the possible physical origin of the diverse properties observed in $\mathrm{Ge}_{1-\mathrm{x}} \mathrm{Sn}_{\mathrm{x}}$ layers grown using various techniques, such as the thermal stability ${ }^{1}$ or the types of electronic defects. ${ }^{2}$ Theoretical analyses ${ }^{3,4}$ and experimental $\mathrm{Ge}_{1-\mathrm{x}} \mathrm{Sn}_{\mathrm{x}}$ growth/strain relaxation studies ${ }^{5-7}$ suggest the formation of either $\alpha$-Sn substitutional defects, fullvacancy (FV) structures, Sn interstitials, Sn pair-defects (SS), Sn-split vacancy complexes (SV), or 7-Sn clusterdefects (CD). In the $\alpha$-Sn defects, the Sn atoms occupy substitutional sites in the Ge lattice; the same occurs in the SS and FV structures, but with another Sn atom or a Ge vacancy, respectively, as first neighbor. The SV or CD structures have an octahedral coordination, with $\mathrm{Sn}$ atoms surrounded by six Ge or $\mathrm{Sn}$ atoms, respectively. The $\mathrm{Sn}$ incorporation configuration influences the $\mathrm{Ge}_{1-\mathrm{x}} \mathrm{Sn}_{\mathrm{x}}$

\footnotetext{
a)Phone: +32 16 281818. Fax: +32 16 281706. E-mail: federica.gencarelli@ imec.be.

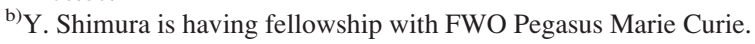

crystallographic, electrical, and optical properties. ${ }^{8,10}$ For example, theoretical investigations ${ }^{9}$ show that the presence of SV complexes increases the minimum $\mathrm{Sn}$ concentration needed to have direct bandgap $\mathrm{Ge}_{1-\mathrm{x}} \mathrm{Sn}_{\mathrm{x}}$. Therefore, recognizing and controlling the presence of specific Sn-vacancy complexes, Sn clusters (i.e., aggregations of two or more Sn atoms directly bonding), or Sn interstitials is also important from an application point of view. Rutherford backscattering and channeling spectrometry (RBS/C) experiments and (224) X-ray diffraction reciprocal space mapping (XRD $\mathrm{RSM}$ ) analyses ${ }^{11}$ indicate that $\mathrm{Sn}$ atoms are substitutionally incorporated in our $\mathrm{Ge}_{1-\mathrm{x}} \mathrm{Sn}_{\mathrm{x}}$ layers. However, RBS and $\mathrm{XRD}$ reveal the average structure of the solid. Even when a high channeling degree is observed by RBS and the average lattice parameter determined by XRD is preserved, it is likely that several atoms are not perfectly located on the lattice sites. As a consequence, a macroscopically ordered material may still exhibit a certain degree of local disorder at the atomic level or contain Sn clusters or Sn-vacancy complexes. In addition, XRD mainly provides information about the coherent portions of the material, ignoring disordered regions. It is clear that a detailed description of the local complexity of the atomic configuration and composition around the $\mathrm{Sn}$ atoms is still missing. Extended X-ray Absorption Fine Structure $^{12}$ (EXAFS) is sensitive to the nature, number, and distance of the neighboring atoms around a target atom. It allows experimentally establishing the local environment of the $\mathrm{Sn}$ atoms in the $\mathrm{Ge}_{1-\mathrm{x}} \mathrm{Sn}_{\mathrm{x}}$ layers, thus 
addressing the existence of complexes, clusters or interstitials. Therefore, this work presents an EXAFS investigation of the local atomic structure around the Sn atoms in both strained and relaxed $\mathrm{Ge}_{1-\mathrm{x}} \mathrm{Sn}_{\mathrm{x}}$ layers with different compositions and thicknesses in order to understand their exact incorporation in the Ge lattice and how they are influenced by strain. In this context, the alloying-induced strain accommodation behavior of $\mathrm{Ge}_{1-\mathrm{x}} \mathrm{Sn}_{\mathrm{x}}$ is discussed.

\section{EXPERIMENTAL DETAILS}

We investigate 17 monocrystalline $\mathrm{Ge}_{1-\mathrm{x}} \mathrm{Sn}_{\mathrm{x}}(0.06 \leq \mathrm{x}$ $\leq 0.124$, as determined by (224) XRD RSM) layers grown on Ge virtual substrates ${ }^{13}$ via atmospheric pressure chemical vapor deposition (CVD) at $320^{\circ} \mathrm{C}^{14}$ The thickness of the $\mathrm{Ge}_{1-\mathrm{x}} \mathrm{Sn}_{\mathrm{x}}$ layers increases from 45 to $542 \mathrm{~nm}$, as determined from the fringes visible in the XRD (004) $2 \theta-\omega$ scans of the fully strained layers or by differential mass measurements and scanning or transmission electron microscopy inspection of the strain relaxed ones. The strain relaxation degrees (SRDs) of these layers vary in the range of $0 \%-71 \%$. Such

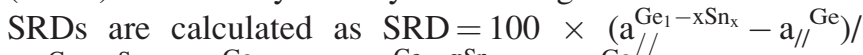
$\left(\mathrm{a}_{0} \mathrm{Ge}_{1}-\mathrm{xSn_{ \textrm {x } }}-\mathrm{a}_{/ /}^{\mathrm{Ge}}\right)$, where $\mathrm{a}_{/ /}^{\mathrm{Ge}}-\mathrm{xSn_{ \textrm {x } }}$ and $\mathrm{a}_{/ /}{ }^{\mathrm{Ge}}$ are the in-plane $\mathrm{Ge}_{1-\mathrm{x}} \mathrm{Sn}_{\mathrm{x}}$ and Ge lattice constants, respectively, as determined by (224) XRD RSM. $a_{0}{ }^{G e_{1}-x n_{x}}$ is the relaxed $\mathrm{Ge}_{1-\mathrm{x}} \mathrm{Sn}_{\mathrm{x}}$ lattice constants of the grown layers, calculated as $\mathrm{a}_{0} \mathrm{Ge}_{1}-\mathrm{xSn}_{\mathrm{x}}=\left(\mathrm{a}_{\perp} \mathrm{Ge}_{1}-\mathrm{xSn} \mathrm{n}_{\mathrm{x}}+2 \quad \mathrm{a}_{/ /}^{\mathrm{Ge}_{1}-\mathrm{xSn}_{\mathrm{x}}} \mathrm{C}_{12} / \mathrm{C}_{11}\right) /\left(1+2 \quad \mathrm{C}_{12} /\right.$ $\left.\mathrm{C}_{11}\right) . \mathrm{a}_{\perp} \mathrm{Ge}_{1}-\mathrm{xSn} \mathrm{n}_{\mathrm{x}}$ is the out-of-plane $\mathrm{Ge}_{1-\mathrm{x}} \mathrm{Sn}_{\mathrm{x}}$ lattice constant, as determined by (224) XRD RSM. $\mathrm{C}_{11}$ and $\mathrm{C}_{12}$ are the $\mathrm{Ge}_{1-\mathrm{x}} \mathrm{Sn}_{\mathrm{x}}$ elastic constants in the contracted index notation.

EXAFS data were collected at the Dutch-Belgian Beamline DUBBLE (BM26A $)^{15}$ of the European Synchrotron Radiation Facility (ESRF, Grenoble, France), operating in uniform mode, with a current of 160-200 mA. EXAFS signals were measured in fluorescence mode at the Sn K-edge $(29.2 \mathrm{keV})$ using a nine-channel Ge detector. Data were collected up to a wave number $\mathrm{k}=15 \AA^{-1}$ in ambient conditions under a relative grazing incidence configuration of $\sim 10^{\circ}$, with typical acquisition times of $45 \mathrm{~min}$ (i.e., 1-20 s per data point). Three spectra were averaged to improve the signal to noise ratio. Some glitches systematically appeared in the EXAFS signals, especially for thin samples, probably due to parasitic diffraction originating from the high crystallinity and the strong epitaxial character of the deposited layers. The appearance of these glitches was minimized by carefully rotating the samples in the X-ray beam in order to avoid the diffraction conditions and by software and manual deglitching. However, the quality of the EXAFS of the thinner films was affected by this issue and their useful signal was limited to $\mathrm{k}=9-10 \AA^{-1}$. As a consequence, the data corresponding to the thinner films exhibit the larger error bars. Data reduction of the experimental $\mathrm{X}$-ray absorption spectra was performed with the program EXBROOK21. ${ }^{16}$ Background subtraction and normaliza$\operatorname{tion}^{17}$ was carried out by fitting (i) a linear polynomial to the pre-edge region in order to remove any instrumental background and absorption effects from other edges and (ii) cubic splines simulating the absorption coefficient from an isolated atom to the post-edge region. EXAFS refinements were performed with the EXCURVE package. ${ }^{16}$ Phase shifts and backscattering factors were calculated $a b$ initio using HedinLundqvist potentials. ${ }^{18}$

\section{RESULTS AND DISCUSSION}

The structural results of the Sn K-edge EXAFS refinements of the investigated $\mathrm{Ge}_{1-\mathrm{x}} \mathrm{Sn}_{\mathrm{x}}$ materials are summarized in Table I. All the obtained $\mathrm{k}^{3}$-weighted EXAFS spectra are plotted as a function of the wave number k in Fig. 1 and all the Fourier Transforms (FT) of the $\mathrm{k}^{3}$ weighted EXAFS spectra are plotted as a function of the radial distance $\mathrm{d}$ from a central Sn atom in Fig. 2. For every sample, the phasecorrected FT of the $\mathrm{k}^{3}$-weighted EXAFS signal plot shows a main peak at $\sim 2.6 \AA$, corresponding to a first-neighbor (1NN) Ge atomic shell around a representative Sn atom. The fitted $\mathrm{Sn}-\mathrm{Ge} 1 \mathrm{NN}$ distances $\mathrm{d}_{\mathrm{SnGe}}$ vary between 2.59 and $2.64 \AA$. A second peak at $\sim 4.0 \AA$ is also observed, corresponding to a second-neighbor (2NN) mixed $\mathrm{Ge} / \mathrm{Sn}$ atomic shell. The fitted $2 \mathrm{NN} \mathrm{Sn}-\mathrm{Ge}$ distances $\mathrm{d}_{\mathrm{SnGe}}$ vary between 4.00 and $4.10 \AA$. The $2 \mathrm{NN}$ Sn-Sn distances $\mathrm{d}_{\mathrm{SnSn}}$ vary between 3.98 and $4.11 \AA$. Finally, a third peak observed at $\sim 4.7 \AA$ is associated to a Ge third-neighbor ( $3 \mathrm{NN}$ ) atomic shell. The fitted $3 \mathrm{NN}$ Sn-Ge distances $\mathrm{d}_{\mathrm{SnGe}}$ vary between 4.65 and $4.81 \AA$. However, the abovementioned limited k-range $\left(9-10 \AA^{-1}\right)$ of the thinner layers does not allow including a third shell in their EXAFS model. In addition, the data quality does not allow determining whether $\mathrm{Sn}$ atoms are also present in the third shells.

For the samples with a useful signal extending beyond $\mathrm{k}=12 \AA^{-1}$, the quality of the fittings can be further improved by including the contribution of an $\mathrm{O}$ shell at a distance $\mathrm{d}_{\mathrm{SnO}}$ between 2.09 and $2.21 \AA$ and of a Sn shell at a distance $d_{\text {SnSn }}$ between 3.20 and $3.50 \AA$. These distances, presented in Fig. 3 as a function of the Sn content and the SRDs of the underlying $\mathrm{Ge}_{1-\mathrm{x}} \mathrm{Sn}_{\mathrm{x}}$ layers, correspond to averages of the typical $\mathrm{Sn}-\mathrm{O}$ and $\mathrm{Sn}-\mathrm{Sn}$ distances found in $\mathrm{SnO}$ $\left(2.22 \AA\right.$ and $3.50 \AA$, respectively) and in $\mathrm{SnO}_{2}(2.05 \AA$ and $3.20 \AA$, respectively). ${ }^{19}$ This indicates that a native oxide in which the surroundings of the $\mathrm{Sn}$ atoms are similar to those found in the pure Sn oxides is likely present at the surface of the $\mathrm{Ge}_{1-\mathrm{x}} \mathrm{Sn}_{\mathrm{x}}$ films. Although this oxide layer is likely very thin $(\sim 1-3 \mathrm{~nm})$, grazing incidence significantly increases the effective distance travelled by the X-rays in this layer, thus enhancing their absorption probability. The presence of a $\mathrm{Ge}_{1-\mathrm{x}} \mathrm{Sn}_{\mathrm{x}}$ native oxide on these samples was confirmed by XPS analysis, which also revealed that the $\mathrm{Sn}$ atoms exhibit a larger propensity to oxidation than the Ge atoms, resulting in higher $\mathrm{Sn} / \mathrm{Ge}$ ratios in the oxide as compared to the underlying $\mathrm{Ge}_{1-\mathrm{x}} \mathrm{Sn}_{\mathrm{x}}$ layer.

\section{A. Sn incorporation's configuration in the Ge lattice}

The fitted 1NN Sn-Ge distances $\mathrm{d}_{\mathrm{SnGe}}$, which correspond to the Sn-Ge bond length $\mathrm{R}_{\mathrm{GeSn}}$, are plotted as a function of the Sn content and for different SRDs in Fig. 4. These $d_{\text {SnGe }}$ values are slightly shorter than the sum of the covalent radii of $\mathrm{Ge}$ and $\mathrm{Sn}$ (i.e., $\mathrm{r}_{\mathrm{Ge}}+\mathrm{r}_{\mathrm{Sn}}=1.225 \AA+1.405 \AA=2.63 \AA$ ) 
TABLE I. Summary of the structural results of the Sn K-edge EXAFS refinements of the $\mathrm{Ge}_{1-\mathrm{x}} \mathrm{Sn}_{\mathrm{x}}$ materials along with the corresponding native oxides (which comprise $\mathrm{Sn}$ atoms that are not included into the $\mathrm{Ge}_{1-\mathrm{x}} \mathrm{Sn}_{\mathrm{x}}$ layers models). For analysis purposes, the $\mathrm{Ge}_{1-\mathrm{x}} \mathrm{Sn}_{\mathrm{x}}$ samples are grouped in four classes (A, B, C, and D) with increasing average strain relaxation degrees (2\%, 24\%, 45\%, and 68\%). Each class is characterized by increasing indices (between 1 and 5) associated with increasing $\mathrm{SnCl}_{4} / \mathrm{Ge}_{2} \mathrm{H}_{6}$ partial pressure ratios (between 0.04 and 0.24 ) employed to grow the corresponding samples, corresponding to increasing nominal Sn contents. $\mathrm{h}=$ thickness of the $\mathrm{Ge}_{1-\mathrm{x}} \mathrm{Sn}_{\mathrm{x}}$ layer. $\mathrm{SRD}=$ strain relaxation degree of the $\mathrm{Ge}_{1-\mathrm{x}} \mathrm{Sn}_{\mathrm{x}}$ layer. $\mathrm{E}_{\mathrm{f}}=$ correction of the zero photoelectron wave vector relative to the origin of $\mathrm{k} . \mathrm{k}_{\max }=$ maximum photoelectron wave number included in the fitting. $\mathrm{N}_{\mathrm{i}}=$ coordination number and element type of the $i$ th atomic shell included in the fitting model. $\mathrm{d}_{\mathrm{i}}=$ radial distance of the neighboring atoms in the $i$ th shell. $\mathrm{A}_{\mathrm{i}}=$ Debye-Waller term of the $i$ th shell $\left(\mathrm{A}=2 \sigma^{2}\right.$, with $\sigma=$ Debye-Waller disorder factor, i.e., the mean square deviation of the radial distance d). $\mathrm{i}=1$ : first neighbors $\mathrm{Ge}_{\text {atomic }} \mathrm{shell}$ in the $\mathrm{Ge}_{1-\mathrm{x}} \mathrm{Sn}_{\mathrm{x}} \operatorname{layer}$. $\mathrm{i}=2$ or 3 : second neighbors $\mathrm{Sn}$ or Ge atomic shell in the $\mathrm{Ge}_{1-\mathrm{x}} \mathrm{Sn}_{\mathrm{x}}$ layer. $\mathrm{i}=4$ : third neighbors $\mathrm{Ge} / \mathrm{Sn}$ atomic shell in the layer. $\mathrm{i}=5$ or 6: first neighbors $\mathrm{Sn}$ or $\mathrm{O}$ atomic shell in the native oxide layer. $\mathrm{i}=7$ : first neighbors $\mathrm{Sn}$ atoms in the $\mathrm{Ge}_{1-\mathrm{x}} \mathrm{Sn}_{\mathrm{x}}$ layer. Numbers in brackets represent the absolute error on the last significant cipher. (x) error: the fit quality was not high enough to obtain significant values. The amplitude reduction factor due to many-electron processes (AFAC) was calibrated with a Sn metal foil and set to 1 for all samples. $\mathrm{r}=\sum_{j}\left(\text { data }_{j}-\text { fit }_{j}\right)^{2} / \sum_{j}\left(\text { data }_{j}\right)^{2}$ : fitting agreement factor.

\begin{tabular}{|c|c|c|c|c|c|}
\hline \multicolumn{2}{|l|}{ Sample } & $\mathrm{A} 2$ & A3 & A4 & A5 \\
\hline At. $\% \mathrm{Sn}$ & & 7.2 & 8.1 & 9.1 & 10.5 \\
\hline $\mathrm{h}(\mathrm{nm})$ & & 68 & 45 & 59 & 45 \\
\hline SRD (\%) & & 4 & 1 & 3 & 0 \\
\hline $\mathrm{E}_{\mathrm{f}}(\mathrm{eV})$ & & $-6.6(x)$ & $-16.2(\mathrm{x})$ & $-10.0(\mathrm{x})$ & $-10.5(\mathrm{x})$ \\
\hline $\mathrm{k}_{\max }\left(\AA^{-1}\right)$ & & 10 & 9.5 & 9.7 & 9.5 \\
\hline $\mathrm{N}_{1}$ & & $4.0(9) \mathrm{Ge}$ & $3.6(9) \mathrm{Ge}$ & $4.0(8) \mathrm{Ge}$ & $3.9(8) \mathrm{Ge}$ \\
\hline $\mathrm{d}_{1}(\AA)$ & & $2.58(2)$ & $2.64(3)$ & $2.61(1)$ & $2.6(1)$ \\
\hline$A_{1}\left(\AA^{-2}\right)$ & & $0.013(5)$ & $0.009(6)$ & $0.01(3)$ & 0.013 \\
\hline $\mathrm{N}_{2}$ & & $1.8(\mathrm{x}) \mathrm{Sn}$ & $1.6(\mathrm{x}) \mathrm{Sn}$ & $1.4(\mathrm{x}) \mathrm{Sn}$ & $1.0(5) \mathrm{Sn}$ \\
\hline $\mathrm{d}_{2}(\AA)$ & & $4.00(9)$ & $4.08(9)$ & $4.11(6)$ & $4.01(9)$ \\
\hline $\mathrm{A}_{2}\left(\AA^{-2}\right)$ & & $0.001(2)$ & $0.001(1)$ & $0.006(\mathrm{x})$ & $0.001(1)$ \\
\hline $\mathrm{N}_{3}$ & & $3.1(\mathrm{x}) \mathrm{Ge}$ & $1.8(\mathrm{x}) \mathrm{Ge}$ & $2.7(\mathrm{x}) \mathrm{Ge}$ & $2.3(8) \mathrm{Ge}$ \\
\hline $\mathrm{d}_{3}(\AA)$ & & $4.02(9)$ & $4.08(9)$ & $4.10(3)$ & $4.04(4)$ \\
\hline $\mathrm{A}_{3}\left(\AA^{-2}\right)$ & & $0.001(2)$ & $0.003(1)$ & $0.005(9)$ & 0.001 \\
\hline $\mathrm{N}_{4}$ & & $\ldots$ & $\ldots$ & $\ldots$ & $\ldots$ \\
\hline $\mathrm{d}_{4}(\AA)$ & & $\ldots$ & $\ldots$ & $\ldots$ & $\ldots$ \\
\hline $\mathrm{A}_{4}\left(\AA^{-2}\right)$ & & $\ldots$ & $\ldots$ & $\ldots$ & $\ldots$ \\
\hline $\mathrm{N}_{5}$ & & $\ldots$ & $\ldots$ & $\ldots$ & $\ldots$ \\
\hline $\mathrm{d}_{5}(\AA)$ & & $\ldots$ & $\ldots$ & $\ldots$ & $\ldots$ \\
\hline $\mathrm{A}_{5}\left(\AA^{-2}\right)$ & & $\ldots$ & $\ldots$ & $\ldots$ & $\ldots$ \\
\hline $\mathrm{N}_{6}$ & & $\ldots$ & $\ldots$ & $\ldots$ & $\ldots$ \\
\hline $\mathrm{d}_{6}(\AA)$ & & $\ldots$ & $\ldots$ & $\ldots$ & $\ldots$ \\
\hline $\mathrm{A}_{6}\left(\AA^{-2}\right)$ & & $\ldots$ & $\ldots$ & $\ldots$ & $\ldots$ \\
\hline $\mathrm{N}_{7}$ & & $\ldots$ & $\ldots$ & $\ldots$ & $\ldots$ \\
\hline $\mathrm{d}_{7}(\AA)$ & & $\ldots$ & $\ldots$ & $\ldots$ & $\ldots$ \\
\hline$A_{7}\left(\AA^{-2}\right)$ & & $\ldots$ & $\ldots$ & $\ldots$ & $\ldots$ \\
\hline $\mathrm{r}(\%)$ & & $40 \%$ & $33 \%$ & $22 \%$ & $17 \%$ \\
\hline Sample & B1 & $\mathrm{B} 2$ & B3 & B4 & B5 \\
\hline At. $\% \mathrm{Sn}$ & 6.7 & 6.8 & 8.5 & 9.5 & 12.0 \\
\hline $\mathrm{h}(\mathrm{nm})$ & 144 & 113 & 112 & 118 & 116 \\
\hline SRD (\%) & 32 & 19 & 24 & 32 & 19 \\
\hline$E_{f}(e V)$ & $-10.3(\mathrm{x})$ & $-12.0(9)$ & $-9.5(9)$ & $-10.5(\mathrm{x})$ & $-4.5(9)$ \\
\hline Kmax & 9.5 & 12 & 12 & 9.5 & 12 \\
\hline $\mathrm{N}_{1}$ & $3.8(8) \mathrm{Ge}$ & 3.7 (7) $\mathrm{Ge}$ & $3.3(5) \mathrm{Ge}$ & $3.0(5) \mathrm{Ge}$ & $3.4(6) \mathrm{Ge}$ \\
\hline $\mathrm{d}_{1}(\AA)$ & $2.60(1)$ & $2.594(9)$ & $2.594(9)$ & $2.604(9)$ & $2.59(1)$ \\
\hline$A_{1}\left(\AA^{-2}\right)$ & 0.009 (3) & $0.009(3)$ & $0.005(2)$ & $0.003(3)$ & 0.007 (2) \\
\hline $\mathrm{N}_{2}$ & $1.6(9) \mathrm{Sn}$ & 2.5 (9) Sn & $1.2(9) \mathrm{Sn}$ & $2.5(9) \mathrm{Sn}$ & 2.5 (9) $\mathrm{Sn}$ \\
\hline $\mathrm{d}_{2}(\AA)$ & $4.10(9)$ & $4.05(6)$ & $4.04(8)$ & $4.02(4)$ & $3.98(3)$ \\
\hline $\mathrm{A}_{2}\left(\AA^{-2}\right)$ & $0.06(x)$ & $0.001(1)$ & $0.001(1)$ & $0.001(1)$ & 0.001 \\
\hline $\mathrm{N}_{3}$ & $2.7(\mathrm{x}) \mathrm{Ge}$ & $4.3(7) \mathrm{Ge}$ & $2.1(9) \mathrm{Ge}$ & $3.2(9) \mathrm{Ge}$ & $2.8(7) \mathrm{Ge}$ \\
\hline $\mathrm{d}_{3}(\AA)$ & $4.10(6)$ & $4.05(5)$ & $4.05(5)$ & $4.02(3)$ & $4.04(4)$ \\
\hline $\mathrm{A}_{3}\left(\AA^{-2}\right)$ & $0.002(\mathrm{x})$ & $0.002(4)$ & $0.001(4)$ & $0.001(9)$ & 0.001 \\
\hline $\mathrm{N}_{4}$ & $\ldots$ & $0.5(5) \mathrm{Ge}$ & $0.4(4) \mathrm{Ge}$ & $\ldots$ & $0.5(3) \mathrm{Ge}$ \\
\hline $\mathrm{d}_{4}(\AA)$ & $\ldots$ & $4.76(5)$ & $4.76(7)$ & $\ldots$ & $4.68(4)$ \\
\hline $\mathrm{A}_{4}\left(\AA^{-2}\right)$ & $\ldots$ & $0.001(4)$ & $0.001(1)$ & $\ldots$ & 0.001 \\
\hline $\mathrm{N}_{5}$ & $\ldots$ & 1.1 (3) $\mathrm{Sn}$ & 0.1 (1) Sn & $\ldots$ & $0.2(2) \mathrm{Sn}$ \\
\hline $\mathrm{d}_{5}(\AA \stackrel{\AA}{\mathrm{O}})$ & $\ldots$ & $3.33(3)$ & $3.40(9)$ & $\ldots$ & $3.50(9)$ \\
\hline $\mathrm{A}_{5}\left(\AA^{-2}\right)$ & $\ldots$ & $0.002(3)$ & $0.002(9)$ & $\ldots$ & 0.002 (1) \\
\hline $\mathrm{N}_{6}$ & $\ldots$ & $0.1(6) \mathrm{O}$ & $0.1(3) \mathrm{O}$ & $\ldots$ & 0.1 (1) $\mathrm{O}$ \\
\hline
\end{tabular}


TABLE I. (Continued.)

\begin{tabular}{|c|c|c|c|c|c|}
\hline Sample & B1 & B2 & B3 & B4 & B5 \\
\hline $\mathrm{d}_{6}(\AA)$ & $\ldots$ & $2.14(2)$ & $2.16(9)$ & $\ldots$ & $2.19(9)$ \\
\hline $\mathrm{A}_{6}\left(\AA^{-2}\right)$ & $\ldots$ & $0.001(2)$ & $0.001(9)$ & $\ldots$ & $0.001(2)$ \\
\hline $\mathrm{N}_{7}$ & $\ldots$ & 0.4 (9) Sn & $\ldots$ & $\ldots$ & 0.3 (7) $\mathrm{Sn}$ \\
\hline $\mathrm{d}_{7}(\AA)$ & $\ldots$ & $3.05(5)$ & $\ldots$ & $\ldots$ & 3.08 (4) \\
\hline $\mathrm{A}_{7}\left(\AA^{-2}\right)$ & $\ldots$ & $0.001(1)$ & $\ldots$ & $\ldots$ & $0.001(1)$ \\
\hline r $(\%)$ & $26 \%$ & $19 \%$ & $22 \%$ & $17 \%$ & $26 \%$ \\
\hline Sample & & $\mathrm{C} 2$ & $\mathrm{C} 3$ & $\mathrm{C} 4$ & \\
\hline At. $\% \mathrm{Sn}$ & & 7.2 & 8.2 & 10.1 & \\
\hline $\mathrm{h}(\mathrm{nm})$ & & 210 & 240 & 213 & \\
\hline $\operatorname{SRD}(\%)$ & & 39 & 52 & 44 & \\
\hline$E_{\mathrm{f}}(\mathrm{eV})$ & & $-9.3(9)$ & $-10.0(9)$ & $-7.4(\mathrm{x})$ & \\
\hline $\operatorname{kmax}\left(\AA^{-1}\right)$ & & 14.5 & 14.5 & 14.5 & \\
\hline $\mathrm{N}_{1}$ & & $3.5(3) \mathrm{Ge}$ & $3.8(3) \mathrm{Ge}$ & $3.1(3) \mathrm{Ge}$ & \\
\hline $\mathrm{d}_{1}(\AA)$ & & $2.592(4)$ & $2.599(5)$ & $2.587(6)$ & \\
\hline $\mathrm{A}_{1}\left(\AA^{-2}\right)$ & & $0.005(1)$ & 0.007 (1) & $0.006(1)$ & \\
\hline $\mathrm{N}_{2}$ & & 1.5 (9) $\mathrm{Sn}$ & 1.5 (9) $\mathrm{Sn}$ & $1.4(7) \mathrm{Sn}$ & \\
\hline $\mathrm{d}_{2}(\AA)$ & & $4.01(2)$ & $4.04(2)$ & $4.03(2)$ & \\
\hline $\mathrm{A}_{2}\left(\AA^{-2}\right)$ & & $0.001(2)$ & $0.001(2)$ & 0.001 (1) & \\
\hline $\mathrm{N}_{3}$ & & $2.9(8) \mathrm{Ge}$ & 2.7 (6) Ge & 2.5 (7) $\mathrm{Ge}$ & \\
\hline $\mathrm{d}_{3}(\AA)$ & & $4.03(2)$ & $4.06(2)$ & $4.04(1)$ & \\
\hline $\mathrm{A}_{3}\left(\AA^{-2}\right)$ & & $0.001(4)$ & $0.001(2)$ & $0.001(3)$ & \\
\hline $\mathrm{N}_{4}$ & & $1.0(9) \mathrm{Ge}$ & $0.4(9) \mathrm{Ge}$ & 0.5 (3) Ge & \\
\hline $\mathrm{d}_{4}(\AA)$ & & $4.65(2)$ & $4.79(2)$ & $4.72(3)$ & \\
\hline $\mathrm{A}_{4}\left(\AA^{-2}\right)$ & & $0.001(1)$ & 0.001 (1) & $0.001(1)$ & \\
\hline $\mathrm{N}_{5}$ & & 0.1 (9) Sn & 0.1 (9) $\mathrm{Sn}$ & 0.1 (1) Sn & \\
\hline $\mathrm{d}_{5}(\AA)$ & & $3.47(3)$ & $3.48(3)$ & $3.37(5)$ & \\
\hline $\mathrm{A}_{5}\left(\AA^{-2}\right)$ & & $0.001(3)$ & $0.001(1)$ & 0.001 (1) & \\
\hline $\mathrm{N}_{6}$ & & $0.2(1) \mathrm{O}$ & $0.1(1) \mathrm{O}$ & $0.1(1) \mathrm{O}$ & \\
\hline $\mathrm{d}_{6}(\AA)$ & & $2.21(4)$ & $2.20(4)$ & $2.10(6)$ & \\
\hline $\mathrm{A}_{6}\left(\AA^{-2}\right)$ & & $0.001(9)$ & $0.001(1)$ & 0.001 (1) & \\
\hline $\mathrm{N}_{7}$ & & $\ldots$ & $\ldots$ & $\ldots$ & \\
\hline $\mathrm{d}_{7}(\AA)$ & & $\ldots$ & $\ldots$ & $\ldots$ & \\
\hline $\mathrm{A}_{7}\left(\AA^{-2}\right)$ & & $\ldots$ & $\ldots$ & $\ldots$ & \\
\hline r $(\%)$ & & $21 \%$ & $18 \%$ & $21 \%$ & \\
\hline Sample & D1 & $\mathrm{D} 2$ & D3 & D4 & D5 \\
\hline At. Sn $\%$ & 6.0 & 7.9 & 8.5 & 10.5 & 12.4 \\
\hline $\mathrm{h}(\mathrm{nm})$ & 542 & 499 & 420 & 305 & 466 \\
\hline $\operatorname{SRD}(\%)$ & 63 & 69 & 64 & 69 & 71 \\
\hline$E_{f}(e V)$ & $-7.4(9)$ & $-11.3(9)$ & $-7.0(9)$ & $-9.9(9)$ & $-6.5(9)$ \\
\hline $\operatorname{Kmax}(\AA)$ & 14.5 & 14.5 & 14.5 & 14.5 & 14.5 \\
\hline $\mathrm{N}_{1}$ & $3.4(4) \mathrm{Ge}$ & $3.7(3) \mathrm{Ge}$ & $3.3(3) \mathrm{Ge}$ & $3.4(2) \mathrm{Ge}$ & $3.1(2) \mathrm{Ge}$ \\
\hline $\mathrm{d}_{1}(\AA)$ & $2.585(9)$ & $2.599(5)$ & $2.593(4)$ & $2.595(5)$ & $2.599(6)$ \\
\hline$A_{1}\left(\AA^{-2}\right)$ & $0.006(6)$ & 0.007 (1) & $0.0054(7)$ & 0.007 (1) & 0.005 (1) \\
\hline $\mathrm{N}_{2}$ & $1.3(9) \mathrm{Sn}$ & $1.8(6) \mathrm{Sn}$ & $1.8(7) \mathrm{Sn}$ & 1.9 (7) $\mathrm{Sn}$ & 1.7 (6) Sn \\
\hline $\mathrm{d}_{2}(\AA)$ & $4.00(2)$ & $4.08(2)$ & $4.01(2)$ & $4.05(2)$ & 4.07 (2) \\
\hline $\mathrm{A}_{2}\left(\AA^{-2}\right)$ & $0.001(1)$ & $0.001(1)$ & $0.001(1)$ & $0.001(1)$ & $0.001(1)$ \\
\hline $\mathrm{N}_{3}$ & $4.8(9) \mathrm{Ge}$ & $3.0(6) \mathrm{Ge}$ & $3.1(7) \mathrm{Ge}$ & $3.3(7) \mathrm{Ge}$ & $2.7(5) \mathrm{Ge}$ \\
\hline $\mathrm{d}_{3}(\AA)$ & $4.02(1)$ & $4.08(1)$ & $4.03(1)$ & $4.06(1)$ & $4.08(2)$ \\
\hline $\mathrm{A}_{3}\left(\AA^{-2}\right)$ & $0.006(1)$ & $0.001(1)$ & $0.001(1)$ & 0.003 & $0.001(2)$ \\
\hline $\mathrm{N}_{4}$ & $0.8(2) \mathrm{Ge}$ & $0.5(2) \mathrm{Ge}$ & $0.7(2) \mathrm{Ge}$ & $0.6(3) \mathrm{Ge}$ & $0.4(2) \mathrm{Ge}$ \\
\hline $\mathrm{d}_{4}(\AA)$ & $4.66(3)$ & $4.79(2)$ & $4.75(2)$ & $4.76(3)$ & $4.81(3)$ \\
\hline $\mathrm{A}_{4}\left(\AA^{-2}\right)$ & 0.001 (1) & $0.001(1)$ & $0.001(1)$ & $0.001(1)$ & 0.001 (1) \\
\hline $\mathrm{N}_{5}$ & $0.2(1) \mathrm{Sn}$ & 0.18 (9) Sn & $0.15(6) \mathrm{Sn}$ & $0.1(1) \mathrm{Sn}$ & 0.17 (9) $\mathrm{Sn}$ \\
\hline $\mathrm{d}_{5}(\AA)$ & $3.46(4)$ & $3.33(3)$ & $3.25(3)$ & $3.37(5)$ & $3.30(2)$ \\
\hline $\mathrm{A}_{5}\left(\AA^{-2}\right)$ & $0.001(3)$ & 0.001 & $0.002(3)$ & 0.001 (1) & 0.001 (1) \\
\hline $\mathrm{N}_{6}$ & $0.4(1) \mathrm{O}$ & $0.3(1) \mathrm{O}$ & $0.4(2) \mathrm{O}$ & $0.2(1) \mathrm{O}$ & $0.2(1) \mathrm{O}$ \\
\hline $\mathrm{d}_{6}(\AA)$ & $2.22(4)$ & $2.14(4)$ & $2.09(4)$ & $2.11(4)$ & $2.11(2)$ \\
\hline
\end{tabular}


TABLE I. (Continued.)

\begin{tabular}{lccccc}
\hline \hline Sample & $\mathrm{D} 1$ & $\mathrm{D} 2$ & $\mathrm{D} 3$ & $\mathrm{D} 4$ & $\mathrm{D} 5$ \\
\hline $\mathrm{A}_{6}\left(\AA^{-2}\right)$ & $0.001(1)$ & $0.003(1)$ & $0.003(8)$ & $0.001(1)$ & $0.001(1)$ \\
$\mathrm{N}_{7}$ & $\ldots$ & $0.1(1) \mathrm{Sn}$ & $\ldots$ & $\ldots$ & $0.1(1) \mathrm{Sn}$ \\
$\mathrm{d}_{7}(\AA)$ & $\ldots$ & $2.89(6)$ & $\ldots$ & $\ldots$ & $2.83(6)$ \\
$\mathrm{A}_{7}\left(\AA^{-2}\right)$ & $\ldots$ & $0.001(1)$ & $26 \%$ & $\ldots$ & $0.001(1)$ \\
$\mathrm{r}(\%)$ & $24 \%$ & $18 \%$ & $17 \%$ & $15 \%$ \\
\hline \hline
\end{tabular}

obtained by halving the accepted equilibrium bond lengths in bulk Ge and $\mathrm{Sn}$ crystals (i.e., $\mathrm{R}_{\mathrm{Ge} 0}=2.45 \AA$ and $\mathrm{R}_{\mathrm{Sn} 0}=2.81 \AA$ ). By definition, covalent radii are expected to be additive for homonuclear single bonds. ${ }^{20}$ However, a perfect covalent radii additivity is not to be expected in the case of heteronuclear bonds, whose length is influenced by the chemical environment around the involved atoms. ${ }^{21,22}$ The shorter GeSn bond lengths observed in this work as compared to the sum of the Ge and $\mathrm{Sn}$ covalent radii might be a consequence of factors such as the alloying-induced strain arising from the insertion of the relatively large $\mathrm{Sn}$ atoms in the $\mathrm{Ge}$ lattice or the partially polar nature of this bond deriving from the different electronegativities of the two atoms. ${ }^{20}$ Following a recent work published by Lang and Smith, ${ }^{21}$ the distance $\mathrm{d}_{\mathrm{GeSn}}$ between covalently bonded $\mathrm{Ge}$ and $\mathrm{Sn}$ atoms in a crystalline structure can be estimated as: $\mathrm{d}_{\mathrm{GeSn}}=\mathrm{r}_{\mathrm{Ge}}+\mathrm{r}_{\mathrm{Sn}}-\mathrm{C}$ $\left|\mathrm{x}_{\mathrm{Ge}}-\mathrm{x}_{\mathrm{Sn}}\right|^{\mathrm{r}}$, with ${ }^{22} \mathrm{C}=0.1 \AA$ and $\mathrm{r}=0.5$. Using $\mathrm{x}_{\mathrm{Ge}}=1.62$ and $\mathrm{x}_{\mathrm{Sn}}=1.49$ as the electronegativity value of $\mathrm{Ge}$ and $\mathrm{Sn}$, respectively, ${ }^{22}$ and $r_{\mathrm{Ge}}=1.225 \AA$ and $\mathrm{r}_{\mathrm{Sn}}=1.405 \AA$ as the Ge and $\mathrm{Sn}$ covalent radii, one obtains $\mathrm{d}_{\mathrm{GeSn}}=2.594 \AA$, which is comparable to the average $\mathrm{d}_{\mathrm{GeSn}}$ value $(2.598 \AA$ ) observed in this work.

The average coordination number of $1 \mathrm{NN}$ Ge atoms in the $\mathrm{Ge}_{1-\mathrm{x}} \mathrm{Sn}_{\mathrm{x}}$ layers is $3.5 \pm 0.5$. This average was calculated after estimating that around $\sim 7 \%$ of the probed $\mathrm{Sn}$ atomsbased on their coordination number-reside in the native oxide. The combination of this finding and of the fitted $\mathrm{R}_{\mathrm{GeSn}}$ values suggests that $S n$ atoms are covalently bonded to four Ge atoms in a tetrahedral configuration. The absence of Sn$\mathrm{Sn}$ dimers or $\mathrm{Sn}$ clusters is indicated by fitted $\mathrm{Sn}-\mathrm{Sn}$ atomic distances values (plotted as a function of the Sn content for different SRDs in Fig. 5) close to $\sim 4.0 \AA$, i.e., much higher than the sum of two Sn covalent radii $\left(2 \mathrm{r}_{\mathrm{Sn}}=2.81 \AA\right)$.

The Sn-Sn distances are comparable to the mostprobable 1NN distance that the $\mathrm{Sn}$ atoms should have in a random $\mathrm{Ge}_{1-\mathrm{x}} \mathrm{Sn}_{\mathrm{x}}$ solid solution, ${ }^{23}$ i.e., $\mathrm{d}_{\mathrm{SnSn} 0}=(1 /(2 \mathrm{pi}$ $\left.\left.\mathrm{C}_{0}\right)\right)^{1 / 3}$, where $\mathrm{C}_{0}$ is the volume concentration of the $\mathrm{Sn}$ atoms. For $\mathrm{x}$ values between 0.06 and 0.124 , the $\mathrm{d}_{\mathrm{SnSn0}}$ values are distributed between 4 and $3 \AA$. However, the fitted $\mathrm{d}_{\text {SnSn }}$ values are close to $4.0 \AA$, irrespective of the Sn content (or the SRD). This occurs because the possible atomic distances between substitutional atoms in a crystalline material are discrete. Therefore, the $\mathrm{Sn}$ atoms are obliged to sit either as $1 \mathrm{NN}\left(\mathrm{d}_{\mathrm{SnSn} 0}=\sim 2.8 \AA\right)$ or as $2 \mathrm{NN}\left(\mathrm{d}_{\mathrm{SnSn} 0}=\sim 4 \AA\right)$ in order to keep their substitutionality. Our analysis indicates that the situation with the $\mathrm{Sn}$ atoms being substitutional and $2 \mathrm{NN}$ is preferred, possibly due to the repulsive force theoretically expected between substitutional $\mathrm{Sn}$ atoms. ${ }^{24}$
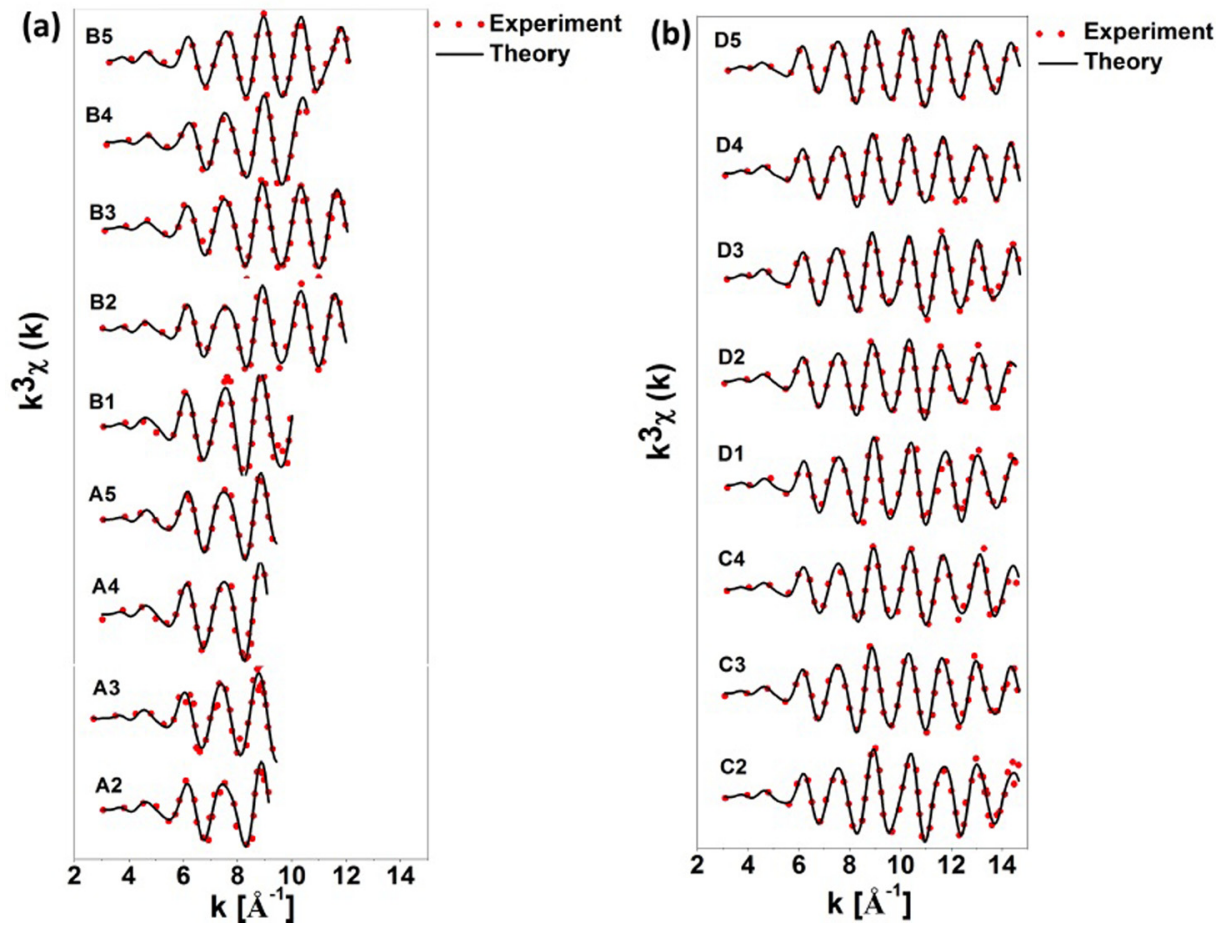

FIG. 1. $\mathrm{k}^{3}$-weighted EXAFS spectra versus reciprocal coordinate $\mathrm{k}$ of the $\mathrm{GeSn}$ investigated thin films. The solid lines are the experimental data and the dotted lines are the best fit. 

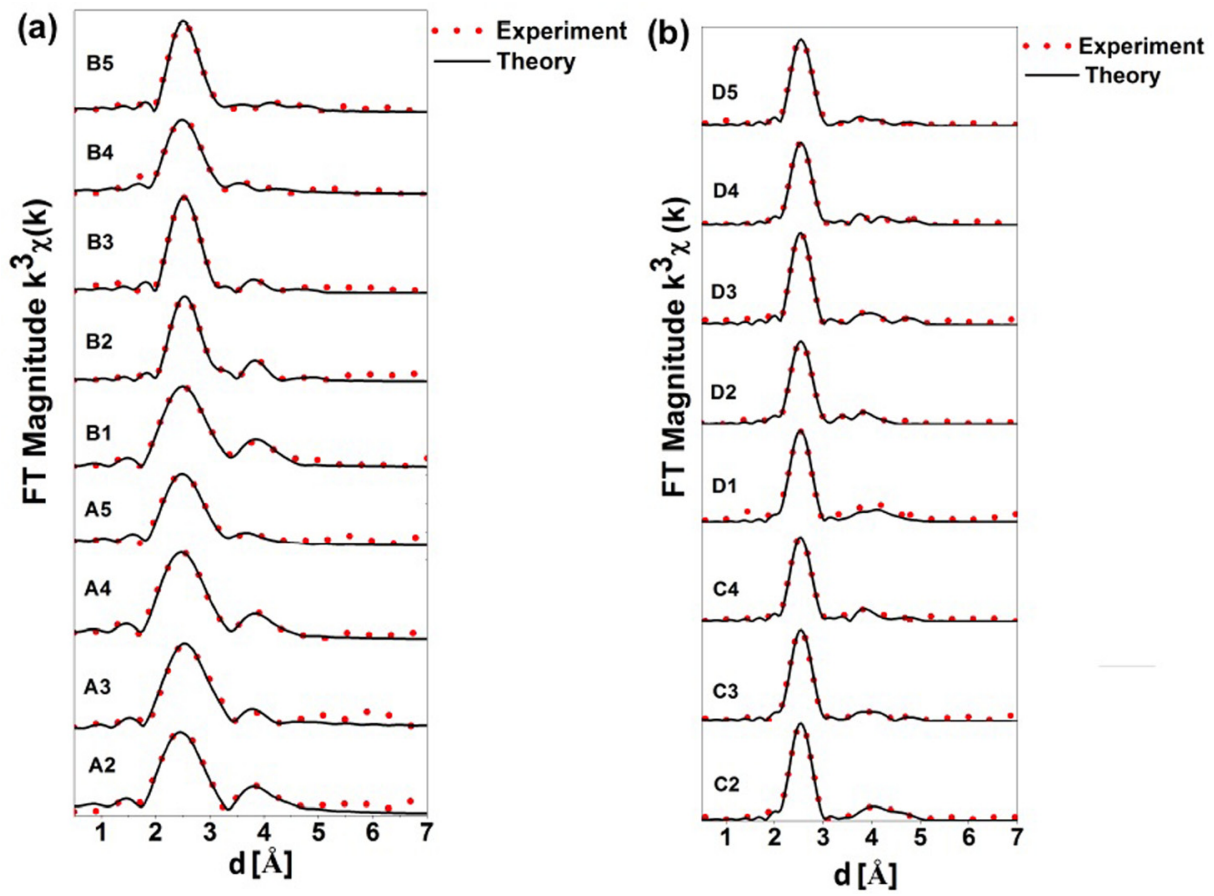

FIG. 2. Fourier Transforms of the $\mathrm{k}^{3}$ weighted EXAFS spectra versus radial distance $\mathrm{d}$ of the GeSn investigated thin films. The solid lines are the experimental data and the dotted lines are the best fit.

The $\mathrm{Ge}_{1-\mathrm{x}} \mathrm{Sn}_{\mathrm{x}}$ samples with the lowest $\mathrm{Sn}$ content have the lowest coordination number for the $2 \mathrm{NN} \mathrm{Sn}$ atoms. Complementarily, these samples have the highest coordination number for the $2 \mathrm{NN}$ Ge atoms. This situation is depicted in Fig. 6, where the increasing (decreasing) coordination numbers of the $2 \mathrm{NN} \mathrm{Sn}(\mathrm{Ge})$ atoms around a central $\mathrm{Sn}$ atom are plotted as a function of the Sn content for the most strain relaxed $\mathrm{Ge}_{1-\mathrm{x}} \mathrm{Sn}_{\mathrm{x}}$ samples. This suggests that the analyzed $\mathrm{Ge}_{1-\mathrm{x}} \mathrm{Sn}_{\mathrm{x}}$ materials are random homogeneous alloys, in which samples with a lower $\mathrm{Sn}$ concentration have more

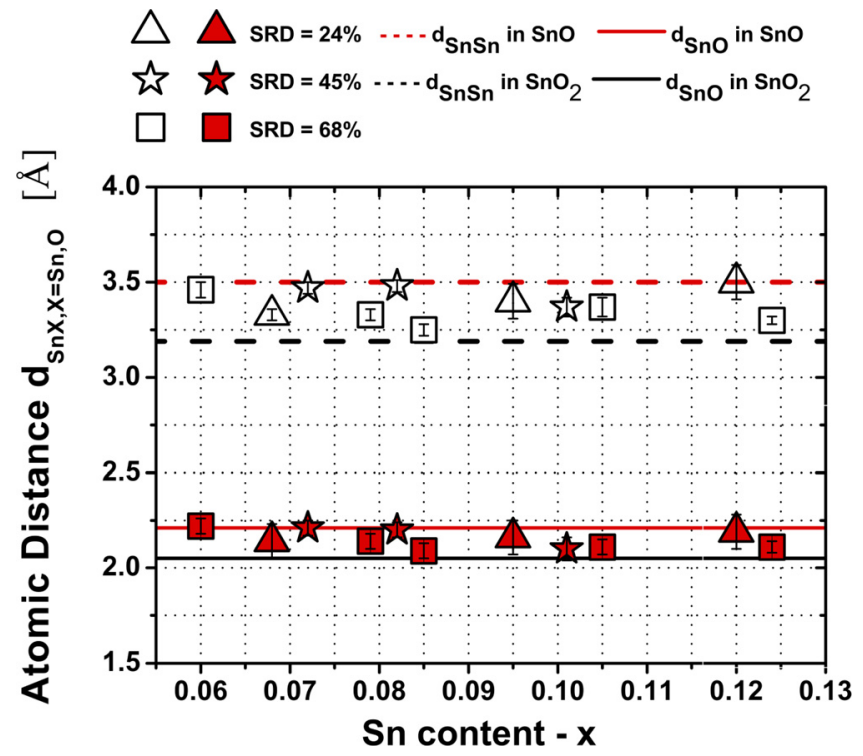

FIG. 3. Fitted atomic distances between a central $\mathrm{Sn}$ atom and other $\mathrm{Sn}$ atoms (open markers) or $\mathrm{O}$ atoms (filled markers) in the native oxides as a function of the Sn content and for different SRDs. As a reference, common $1 \mathrm{NN}$ distances between a central $\mathrm{Sn}$ atom and other $\mathrm{Sn}$ atoms $\left(\mathrm{d}_{\mathrm{SnSn}}\right.$, dashed lines) or $\mathrm{O}$ atoms ( $\mathrm{d}_{\mathrm{SnO}}$, solid lines) in $\mathrm{SnO}$ (red) and $\mathrm{SnO}_{2}$ (black) are also shown. separated Sn atoms and exhibit a relative higher abundance of $\mathrm{Ge}$ atoms in the $2 \mathrm{NN}$ atomic shells around the $\mathrm{Sn}$ atoms. This observation is expected to have a general validity for the investigated samples. However, the relatively large error bars on the coordination numbers only allow to observe this variation for the thicker, more strain relaxed samples, which are characterized by the highest data quality.

It should be mentioned that in four samples (B2, B5, D2, and D5) a weak EXAFS contribution attributed to $1 \mathrm{NN}$ $\mathrm{Sn}$-Sn distances can be included in the fit, revealing the existence of a minute quantity of Sn dimers. Such a minute quantity of dimers only involves $\sim 2.5 \%$ of the total $\mathrm{Sn}$ atoms, as estimated from the coordination number of these 1NN Sn atoms. In one of these samples (D5), the value of the fitted 1NN Sn-Sn distance $\left(\mathrm{d}_{\mathrm{SnSn}}=2.83 \AA\right)$ is close to the

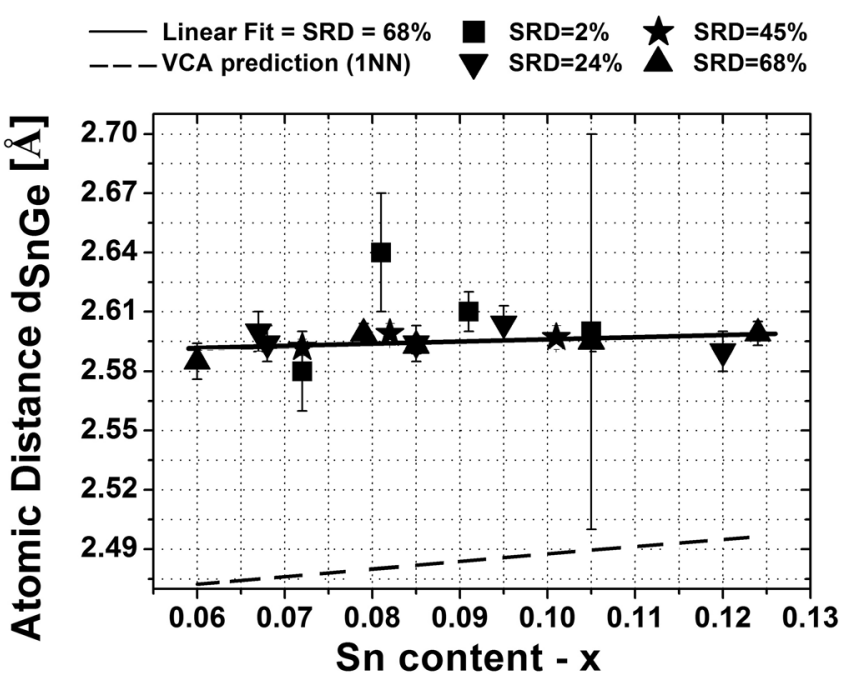

FIG. 4. Experimental (fitted) and VCA-predicted 1NN Sn-Ge distance as a function of the Sn content, for different SRD. 


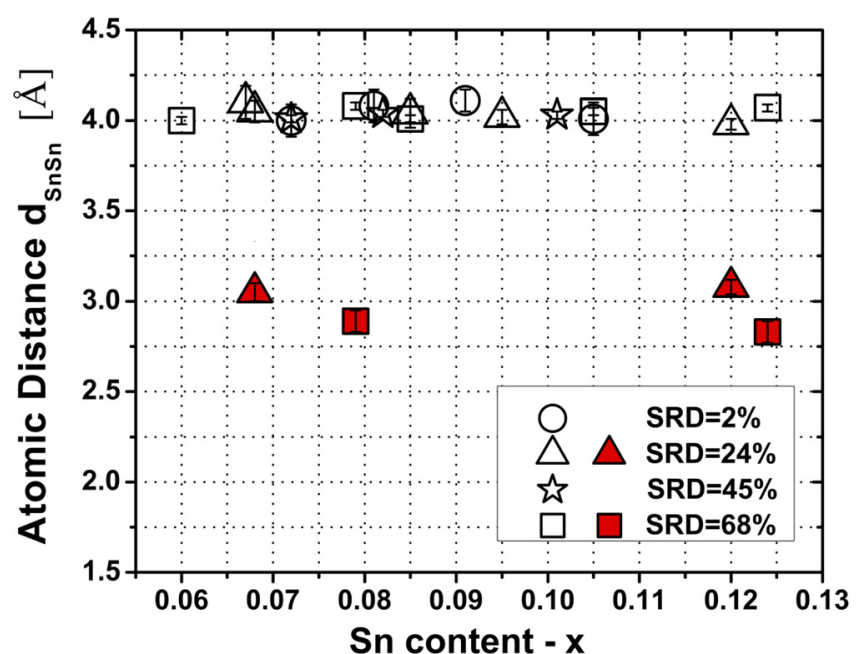

FIG. 5. Fitted atomic distances between the central Sn atom and 1NN (filled markers) or $2 \mathrm{NN}$ (open markers) Sn atoms as a function of the Sn content and for different SRDs.

equilibrium bond length in bulk $\alpha$-Sn $\left(\mathrm{R}_{\mathrm{Sn} 0}=2.81 \AA\right)$. This suggests that the corresponding $\mathrm{Sn}$ atoms occupy neighboring substitutional sites in the $\mathrm{Ge}_{1-\mathrm{x}} \mathrm{Sn}_{\mathrm{x}}$ lattice. In the other three samples, larger $d_{\mathrm{SnSn}}$ are obtained from the fittings (3.08 $\AA$, $3.05 \AA$, and $2.89 \AA$, respectively). This observation indicates that these $\mathrm{Sn}$ atoms likely assume a $\beta$-Sn configuration, which is characterized by $1 \mathrm{NN} \mathrm{Sn}-\mathrm{Sn}$ distances of 3.02 $\AA .^{25}$ The appearance of these $1 \mathrm{NN}$ Sn neighbors and the differences between their distances do not show specific trends with the parameters differentiating the investigated samples, i.e., composition, thickness, and SRD. As a consequence, it is not clear what their origin is or why they are only detected in four layers. The aggregation of substitutional $\mathrm{Sn}$ atoms in the bulk $\mathrm{Ge}_{1-\mathrm{x}} \mathrm{Sn}_{\mathrm{x}}$ layer is unlikely, due to the repulsive force expected between them. ${ }^{24} \mathrm{Sn}$ dimers or clusters might result during $\mathrm{Ge}_{1-\mathrm{x}} \mathrm{Sn}_{\mathrm{x}}$ growth after the random collision of two or more Sn atoms on the surface, followed by their immobilization by the subsequent deposition of Ge atoms. Concentrations lower that $2.5 \%$ of the total $\mathrm{Sn}$ atoms might be incorporated as Sn dimers also in other samples. However, it is not possible to confirm or exclude their presence within the accuracy of these measurements because features related to a

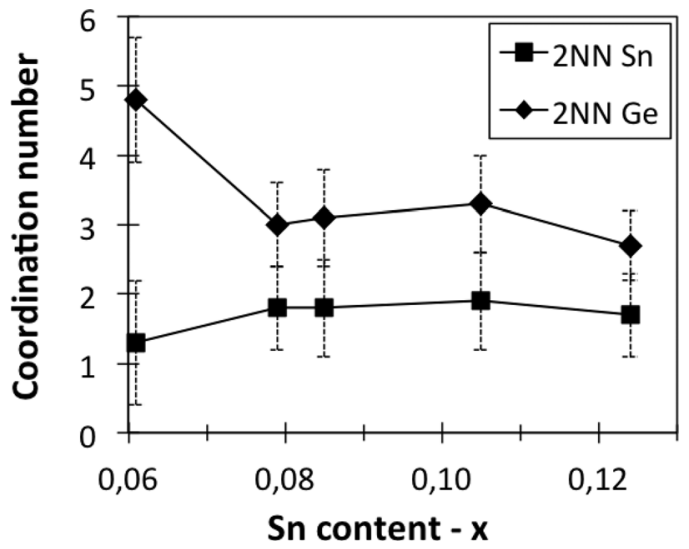

FIG. 6. Decreasing (increasing) coordination number of the $2 \mathrm{NN} \mathrm{Ge}(\mathrm{Sn})$ atoms around a central $\mathrm{Sn}$ atom as a function of $\mathrm{Sn}$ content. small concentration of Sn atoms may have too weak EXAFS signals as compared to the noise to be clearly distinguished.

Analogous considerations are valid for the fraction of $\mathrm{Sn}$ atoms possibly incorporated as interstitials, clusters, or in non-tetrahedral configurations. These defects, if present, are also expected to involve less than $\sim 2.5 \%$ of the total $\mathrm{Sn}$ atoms, as estimated from the minimum coordination number of the $1 \mathrm{NN}$ atoms which can be distinguished. Interstitials Sn atoms would be sitting between lattice sites regularly occupied by $\mathrm{Ge}$ atoms. Therefore, they would result in much shorter 1NN Sn-Ge distances than to the sum of Sn and Ge covalent radii-which were not observed. Similarly, the SV complexes predicted by Ventura et al. ${ }^{3}$ - which would have $\mathrm{d}_{\mathrm{SnGe}}=3.082 \AA$ - were not observed. Hence, the SV complex configuration is not the most favorable one for Sn incorporation in these layers. This finding is advantageous, for example, for the optical applications of $\mathrm{Ge}_{1-\mathrm{x}} \mathrm{Sn}_{\mathrm{x}}$. In fact, the presence of SV complexes would have increased the minimum Sn concentration necessary to achieve a direct bandgap material. ${ }^{9}$ Ventura et $a l .{ }^{3}$ determined a temperaturedependent critical Sn concentration (20 at. \% Sn at room temperature) beyond which the formation of these complexes is favorable in thermal equilibrium. Therefore, one could argue that the Sn concentration in our samples is below the critical concentration needed for the nucleation of the SV complexes at a growth temperature of $320^{\circ} \mathrm{C}$. Ventura ${ }^{3}$ calculated this critical Sn concentration for temperatures up to $131{ }^{\circ} \mathrm{C}$. However, a simple linear extrapolation of such critical Sn concentration at $320^{\circ} \mathrm{C}$ from Ref. 1 provides a value of only 2.3 at. \% Sn, which is significantly lower than the Sn concentration of our samples. This might be attributed to the far-from-equilibrium growth conditions typical of CVD, during which the achievement of energetically favorable situations may be hindered by kinetic constraints. In this case, annealing these metastable $\mathrm{Ge}_{1-\mathrm{x}} \mathrm{Sn}_{\mathrm{x}}$ layers could allow the bulk migration of the incorporated vacancies and/or $\mathrm{Sn}$ atoms, followed by the formation of SV complexes. ${ }^{24}$ Alternatively, the absence of SV complexes may be due to a relatively low density of vacancies in our samples. In fact, their growth temperature of $320^{\circ} \mathrm{C}$ may be sufficiently high to allow the recombination of existing Frenkel defects, i.e., pairs of a vacancy and an interstitial atom. Analogously, Kamiyama et al., ${ }^{26}$ who recently used EXAFS to investigate two $\mathrm{Ge}_{1-\mathrm{x}} \mathrm{Sn}_{\mathrm{x}}$ films grown by molecular beam epitaxy, attributed the absence of SV complexes to a much lower density of vacancies as compared to Sn atoms. In fact, in Ref. 5 (reporting the experimental observation of the SV complexes) a high concentration of vacancies was introduced in the close surroundings of the $\mathrm{Sn}$ atoms as a consequence of the Sn ions implantation in the Ge lattice. Therefore, in that case both the positive energy gain $(0.56 \mathrm{eV}$ (Ref. 5)) expected for the formation of a SV complex as compared to the case of isolated $\mathrm{Sn}$ atoms and vacancies and the proximity between $\mathrm{Sn}$ atoms and numerous vacancies favored the formation of these structures.

The fitted coordination numbers for the $1 \mathrm{NN}$ Ge atoms are slightly lower than the ideal value of 4 . A possible explanation for this reduction might be the presence of vacancies as $1 \mathrm{NN}$ of the $\mathrm{Sn}$ atoms. In fact, Sn atoms effectively attract 
and stabilize vacancies in the Ge lattice in order to locally release part of the induced compressive strain. ${ }^{3,5,8,24}$ However, Fuhr et al. ${ }^{24}$ showed that the resulting FV structures-with one substitutional Sn atom having a vacancy as $1 \mathrm{NN}$ - are not stable. According to their calculations, these structures should spontaneously relax to a SV configuration, which was not detected in this work. Therefore, no vacancies are expected to be present as $1 \mathrm{NN}$ of the substitutional $\mathrm{Sn}$ atoms and the $\alpha$-Sn substitutional defects are expected to be the preferred configuration for the incorporation of $\mathrm{Sn}$ in the Ge lattice with the used growth conditions. Even lower coordination numbers are observed for the 2NN (1.8-6.8, instead of 12) and 3NN (0.4-1, instead of 12) atoms. These fitting results are a direct consequence of the weak intensity for the second and third atomic shells in the FT signals (as visible in Fig. 2, for radial distance values $d>3 \AA$ ). This weak FT intensity may indicate that the second and third shells correspond to few atoms, thus implying the presence of a significant number of Ge vacancies in $\mathrm{Ge}_{1-x} \mathrm{Sn}_{\mathrm{x}}$ in the second and third atomic shells. However, ab initio calculations by Fuhr et l. $^{24}$ show that when a Ge vacancy and a substitutional $\mathrm{Sn}$ atom are separated by one Ge atom there is an energy barrier of only $0.02 \mathrm{eV}$ for the formation of a SV complex. At the growth temperature used for our samples, the available thermal energy-estimated as kT $=\sim 0.05 \mathrm{eV}$ - should be sufficient to overcome this energy barrier. On the one hand, the fact that the SV complexes were not detected in these samples might indicate a contradiction with the theoretical findings in Ref. 24, with a vacancy and a substitutional Sn atom keeping their position when they are separated only by a Ge atom. On the other hand, the low coordination numbers in the $2 \mathrm{NN}$ shells may not be due to the presence of vacancies. The latter option is more reasonable, since the extremely high vacancy concentrations which should be present in order to justify such low coordination numbers are unlikely for these CVD-grown $\mathrm{Ge}_{1-\mathrm{x}} \mathrm{Sn}_{\mathrm{x}}$ layers. No conclusive considerations can be made about this aspect with the current information. Therefore, complementary measurements, such as Positron Annihilation Spectroscopy, may be useful to determine the concentration of vacancies in these $\mathrm{Ge}_{1-\mathrm{x}} \mathrm{Sn}_{\mathrm{x}}$ layers and their configuration around the Sn atoms. An alternative, more likely explanation for the weak FT intensities corresponding to the second and third atomic shells would be a large static disorder present around the Sn atoms. This disorder indicates that $\mathrm{Sn}$ atoms do not have exactly the same position in the Ge lattice and consequently they have slightly different distances from the next neighbors. This situation results in weaker and broader averaged signals as compared to the strong sharp peaks expected for ideal perfect materials. Such disorder is especially significant in the localized amorphous $\mathrm{Ge}_{1-\mathrm{x}} \mathrm{Sn}_{\mathrm{x}}$ regions ${ }^{27}$ present in the investigated layers (as confirmed by TEM inspection ${ }^{27}$ ). In fact, amorphous regions likely contain several different configurations corresponding to very weak EXAFS signals. Finally, it should be mentioned that a relatively light atom such as Ge may not be fully visible at the relatively long distances of $4 \AA$ or $4.7 \AA$ from the scattering $\mathrm{Sn}$ atom, thus contributing to the observed reduction of the coordination numbers.

\section{B. Impact of lattice strain on the $\mathrm{Ge}_{1-\mathrm{x}} \mathrm{Sn}_{\mathrm{x}}$ atomic structure}

The resistance offered by the Ge lattice to the local Snincorporation-induced radial expansion can be described by the topological rigidity parameter ${ }^{28} \mathrm{a}^{* *}$. This parameter ranges between 0 (Vegard limit ${ }^{29}$ ) and 1 (Pauling limit ${ }^{30}$ ) depending on a lattice propensity to change the bond lengths or the bond angles, respectively, in order to accommodate the alloying strain. For $\mathrm{Ge}_{1-\mathrm{x}} \mathrm{Sn}_{\mathrm{x}}$, we obtain ${ }^{31} \mathrm{a}^{* *}=1-\Theta /$ $\left(\mathrm{R}_{\mathrm{Sn} 0}-\mathrm{R}_{\mathrm{Ge} 0}\right)=0.69 \pm 0.29$ using $\Theta=0.11, \mathrm{R}_{\mathrm{Sn} 0}=2.81 \AA$, and $\mathrm{R}_{\mathrm{Ge} 0}=2.45 \AA$. $\Theta=0.11$ represents the slope of the linear fit of the Ge-Sn bond length as a function of the Sn content, as extracted from Fig. 4 for the $\sim 68 \%$ strain-relaxed $\mathrm{Ge}_{1-\mathrm{x}} \mathrm{Sn}_{\mathrm{x}}$ samples (having the highest data quality). $\mathrm{R}_{\mathrm{Sn} 0}$ and $\mathrm{R}_{\mathrm{Ge} 0}$ are the equilibrium bond lengths for bulk $\alpha$-Sn and $\mathrm{Ge}$, respectively. Despite its considerable uncertainty, this $\mathrm{a}^{* *}$ value is in agreement with the one predicted for $\mathrm{Ge}_{1-\mathrm{x}} \mathrm{Sn}_{\mathrm{x}}$ using $a b$ initio calculations $\mathrm{s}^{32}\left(\mathrm{a}^{* *}=0.69\right)$. It indicates that the strain due to alloying in $\mathrm{Ge}_{1-\mathrm{x}} \mathrm{Sn}_{\mathrm{x}}$ is accommodated via both bond stretching and bond bending, with a slight predominance of the latter. Such a predominantly Pauling-type behavior implies that the bond-bending force constant $\beta$ is lower than the bond-stretching force constant $\alpha$. This entails a lower energy required to change the bond angles as compared to the bond lengths in response to shortrange electrostatic atomic interactions. Accordingly, the ratio between the bond-stretching and the bond-bending force constants $(\beta / \alpha)$ extracted from $^{28} \mathrm{a}^{* *}=(1+1.25(\beta / \alpha)) /$ $\left(1+3.60(\beta / \alpha)+1.17(\beta / \alpha)^{2}\right)$ is $\beta / \alpha=0.21$ when using the $\mathrm{Ge}_{1-x} \mathrm{Sn}_{\mathrm{x}}$ topological rigidity parameter experimentally determined in this work.

The $\mathrm{Ge}_{1-\mathrm{x}} \mathrm{Sn}_{\mathrm{x}}$ topological rigidity parameter is slightly larger than the one measured for $\mathrm{Si}_{1-y} \mathrm{Ge}_{\mathrm{y}}$ using EXAFS ${ }^{34}$ $\left(a^{* *}=0.63\right)$, indicating that the $\mathrm{Ge}_{1-\mathrm{x}} \mathrm{Sn}_{\mathrm{x}}$ lattice is slightly less rigid than the $\mathrm{Si}_{1-\mathrm{y}} \mathrm{Ge}_{\mathrm{y}}$ lattice. The lower ratio between the bond-bending and bond-stretching force constant $(\beta / \alpha)$ for $\mathrm{Sn}$ as compared to $\mathrm{Si}$ and $\mathrm{Ge}$ is also theoretically predicted by $a b$ initio DFT calculations. ${ }^{35}$ A predominantly Pauling behavior is typical of a wide range of semiconductor alloys. ${ }^{34,36}$ This is due to the strong repulsive force existing between covalently or ionically bonded atoms, due to the Pauli exclusion principle. Such forces result in rather rigid bonds, which hinder the approach of $2 \mathrm{NN}$ and $3 \mathrm{NN}$ atoms to the fourth and further next neighbors when an impurity atom is introduced. Therefore, the lattice reacts by changing the bond angles in order to minimize the alloying-induced strain. This explains why the distortion in the $\mathrm{Ge}_{1-\mathrm{x}} \mathrm{Sn}_{\mathrm{x}}$ layers investigated in this work is rather local, being limited to the first atomic shell. As a consequence, the observed $2 \mathrm{NN}$ and 3NN distances remain close to those of a pure Ge lattice ( $\sim 4.0$ and $4.7 \AA$, respectively) instead of reaching the larger values that would be caused by a rigid lattice expansion ( $\sim 4.2$ and $5 \AA$, respectively).

The Virtual Crystal Approximation (VCA) model ${ }^{33}$ is based on the assumption that all atoms occupy the average lattice positions defined by the lattice constant, with a linear compositional dependence of bond lengths. As a consequence of the observed mixed Vegard-Pauling behavior of 
$\mathrm{Ge}_{1-\mathrm{x}} \mathrm{Sn}_{\mathrm{x}}$, the Ge-Sn bond length does vary with the composition. However, it varies to a lesser extent than that predicted by the VCA model. In fact, the slope of the linear fit of the Ge-Sn bond length as a function of the Sn content $(\Theta=0.11)$ is lower than the one predicted by the VCA model $\left(\Theta_{\mathrm{VCA}}=0.36\right)$. Here, $\Theta_{\mathrm{VCA}}=0.36$ was extracted from the weighted linear interpolation of the Ge and Sn bond lengths in $\mathrm{Ge}_{1-\mathrm{x}} \mathrm{Sn}_{\mathrm{x}}$, which is plotted as a dashed line in Fig. 4. In addition, substantially higher $\mathrm{R}_{\mathrm{GeSn}}$ values are obtained from the fittings as compared to those predicted by the VCA model (Fig. 4). The observed deviations between the experimental Ge-Sn and Sn-Sn bond lengths and their VCA-predicted values are as large as $6.5 \%$ and $17 \%$, respectively. These discrepancies might explain why the VCA predictions for $\mathrm{Ge}_{1-\mathrm{x}} \mathrm{Sn}_{\mathrm{x}}$ are often in disagreement with the experimental findings. ${ }^{37-41}$ Hence, this knowledge might be used to refine the current band-structure calculations of $\mathrm{Ge}_{1-\mathrm{x}} \mathrm{Sn}_{\mathrm{x}}$ alloys based on the VCA model by including the experimentally determined atomic distances.

VCA-predictions of the band structure of $\mathrm{Si}_{1-y} \mathrm{Ge}_{\mathrm{y}}$ alloys are in better agreement with the experimental findings. ${ }^{42,43}$ One explanation might be that VCA offers a more reliable picture of the atomic structure of $\mathrm{Si}_{1-y} \mathrm{Ge}_{\mathrm{y}}$ than it does of $\mathrm{Ge}_{1-\mathrm{x}} \mathrm{Sn}_{\mathrm{x}}$. In fact, the deviations between the experimental $\mathrm{Ge}-\mathrm{Ge}, \mathrm{Ge}-\mathrm{Si}$, and $\mathrm{Si}-\mathrm{Si}$ bond lengths (as measured by EXAFS) and the average bond length value predicted by the VCA model are lower than $3 \% .^{44,45}$ This lower level of distortion of the local bonding geometry can be attributed to the lower lattice constant and atomic radius mismatch between the involved alloying elements in $\mathrm{Si}_{1-y} \mathrm{Ge}_{\mathrm{y}}$ (4\% and $8 \%$, respectively) as compared to $\mathrm{Ge}_{1-\mathrm{x}} \mathrm{Sn}_{\mathrm{x}}(15 \%$ and $16 \%$, respectively). As pointed out by Maurizio et al., ${ }^{46}$ the VCA models is more suitable to describe the atomic structure of alloys with a relatively small mismatch of the lattice constants and the atomic radii of their constituents. As an example, their EXAFS measurements ${ }^{46}$ show that the VCA model provides a correct picture of the local atomic structure of $\mathrm{Au}_{\mathrm{x}} \mathrm{Ag}_{1-\mathrm{x}}$, where the mismatch of the lattice parameters and the atomic radii of $\mathrm{Au}$ and $\mathrm{Ag}$ is lower than $0.3 \%$.

Structural models use small periodic structures that preserve the chemical identity of the elements and reproduce the main features of the alloy. These models provide better predictions than the VCA model for $\mathrm{Ge}_{1-x} \mathrm{Sn}_{\mathrm{x}}$. For example, structural models based on eight-atom supercells ${ }^{47}$ predict a large and composition-dependent positive bowing for the direct gap in $\mathrm{Ge}_{1-\mathrm{x}} \mathrm{Sn}_{\mathrm{x}}$ alloys, in good agreement with the experimental findings, ${ }^{37,48}$ while a much smaller bowing is predicted by VCA models. ${ }^{49,50}$ However, structural models still fail to provide an accurate atomic description of $\mathrm{Ge}_{1-\mathrm{x}} \mathrm{Sn}_{\mathrm{x}}$. For example, much smaller $\mathrm{R}_{\mathrm{GeSn}}$ values $(\sim 2.47-2.51 \AA)$ have been calculated by Chibane and Ferhat ${ }^{51}$ as compared to the experimental ones determined in this work $(\sim 2.6 \AA)$ for a similar composition range (i.e., $\mathrm{x}=0.0625-0.1250$ ). These discrepancies may be due to the use of a zincblende structure in Ref. 51 instead of a random alloy (as suggested by these EXAFS measurements). Therefore, the results of these EXAFS measurements can be useful to develop more accurate atomistic models of
$\mathrm{Ge}_{1-\mathrm{x}} \mathrm{Sn}_{\mathrm{x}}$ based upon an experimentally verified description of the local surrounding of the Sn atoms.

These EXAFS results do not contradict the validity of Vegard's law for the $\mathrm{Ge}_{1-\mathrm{x}} \mathrm{Sn}_{\mathrm{x}}$ lattice constant. In fact, Vegard's law describes the composition dependence of the average lattice constant $\mathrm{a}_{0} \mathrm{Ge}_{1}-\mathrm{xSn}_{\mathrm{x}}$, resulting from the weighted average of locally varying distances. This average lattice constant is related to the average $\mathrm{Ge}-\mathrm{Sn}$ bond length $(\langle\mathrm{R}(\mathrm{x})\rangle)$ predicted by the VCA model as ${ }^{52} \mathrm{a}_{0} \mathrm{Ge}_{1}-\mathrm{xSn}_{\mathrm{x}}$ $=4\langle\mathrm{R}(\mathrm{x})\rangle / \sqrt{ } 3$. Here, $\langle\mathrm{R}(\mathrm{x})\rangle$ can be calculated from the experimental Sn-Sn, Ge-Ge, and Ge-Sn bond lengths $\left(\mathrm{R}_{\mathrm{SnSn}}\right.$, $\mathrm{R}_{\mathrm{GeGe}}$, and $\mathrm{R}_{\mathrm{GeSn}}$, respectively) as $\langle\mathrm{R}(\mathrm{x})\rangle=\mathrm{x}^{2} \mathrm{R}_{\mathrm{SnSn}}$ $+(1-x)^{2} R_{\mathrm{GeGe}}+2 \mathrm{x}(1-\mathrm{x}) \mathrm{R}_{\mathrm{GeSn}}$. The latter two equations can be used to compare the composition dependence of the $\mathrm{Ge}_{1-\mathrm{x}} \mathrm{Sn}_{\mathrm{x}}$ lattice constant determined by EXAFS and by (224) XRD RSM. Since in this work EXAFS signals were collected at the Sn K-edge, only the $\mathrm{R}_{\mathrm{GeSn}}$ and $\mathrm{R}_{\mathrm{SnSn}}$ values can be experimentally determined. In addition, the $\mathrm{Sn}-\mathrm{Sn}$ bond lengths are only available for a limited number of samples, thus making it difficult to extract an average $\mathrm{R}_{\mathrm{SnSn}}$ value. If the $\mathrm{Ge}_{1-\mathrm{x}} \mathrm{Sn}_{\mathrm{x}}$ layers investigated in these work had a purely Pauling behavior, the Ge-Ge and Sn-Sn bond lengths would be equal to their equilibrium values, i.e., $\mathrm{R}_{\mathrm{GeGe}}=\mathrm{R}_{\mathrm{GeGe}}^{0}=2.45 \AA \quad$ and $\mathrm{R}_{\mathrm{SnSn}}=\mathrm{R}_{\mathrm{SnSn}}^{0}=2.81 \AA$, respectively. However, in such a situation the $\mathrm{Ge}_{1-\mathrm{x}} \mathrm{Sn}_{\mathrm{x}}$ lattice constant predicted by the VCA model would be significantly lower than the one experimentally determined by (224) RSM XRD. This situation is illustrated in Fig. 7, where the curve VCA_R0 represents the VCA-predicted $\mathrm{a}_{0} \mathrm{Ge}_{1}-\mathrm{xSn_{x }}$ value when adopting the equilibrium values of the Ge-Ge and $\mathrm{Sn}-\mathrm{Sn}$ bond lengths to calculate $\langle\mathrm{R}(\mathrm{x})\rangle$. However, the partially Vegard-type behavior indicated by a topological rigidity parameter smaller than unity entails a compositional dependence of the bond lengths. Since EXAFS measurements of $\mathrm{Si}_{1-\mathrm{y}} \mathrm{Ge}_{\mathrm{y}}$ alloys showed that the $\mathrm{Ge}-\mathrm{Ge}, \mathrm{Ge}-\mathrm{Si}$, and $\mathrm{Si}-\mathrm{Si}$ bond lengths in $\mathrm{Si}_{1-y} \mathrm{Ge}_{\mathrm{y}}$ alloys have the same compositional dependence, ${ }^{45,53}$ one might expect that a similar situation is also valid for the bonds in $\mathrm{Ge}_{1-x} \mathrm{Sn}_{\mathrm{x}}$. Indeed, if the same slope of the linear fit of the Ge-Sn bond length as a

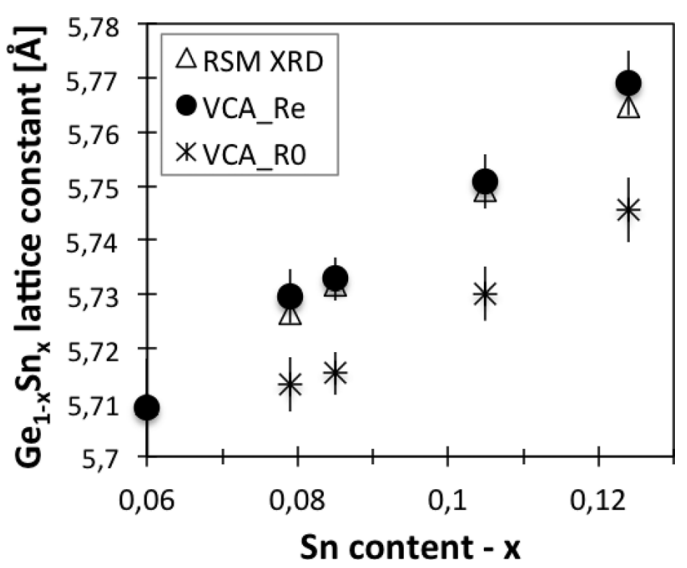

FIG. 7. Comparison between the $\mathrm{Ge}_{1-\mathrm{x}} \mathrm{Sn}_{\mathrm{x}}$ lattice constant determined by (224) RSM XRD and predicted by the VCA model, with $\langle\mathrm{R}(\mathrm{x})\rangle$ calculated using either the equilibrium values of the Ge-Ge and $\mathrm{Sn}-\mathrm{Sn}$ bond lengths $\left(\mathrm{R}_{\mathrm{GeGe}}^{0}\right.$ and $\mathrm{R}_{\mathrm{SnSn}}^{0}$, respectively, for the curve VCA_R0) or their estimated values ( $\mathrm{R}_{\mathrm{GeGe}}^{\mathrm{e}}$ and $\mathrm{R}_{\mathrm{SnSn}}^{\mathrm{e}}$, respectively, for the curve VCA_Re). 
function of the Sn content $(\Theta=0.11)$ is used to estimate the $\mathrm{Ge}-\mathrm{Ge}$ and $\mathrm{Sn}-\mathrm{Sn}$ bond lengths for the calculation of $\langle\mathrm{R}(\mathrm{x})\rangle$, a much better agreement is observed between the $\mathrm{a}_{0} \mathrm{Ge}_{1}-\mathrm{xSn}_{\mathrm{x}}$ values measured by (224) XRD RSM and the ones predicted by the VCA model (represented by the VCA_Re curve in Fig. 7). This suggests that in $\mathrm{Ge}_{1-\mathrm{x}} \mathrm{Sn}_{\mathrm{x}}$ alloys the three different bond types have a similar composition dependence (as it was observed for $\mathrm{Si}_{1-\mathrm{y}} \mathrm{Ge}_{\mathrm{y}}$ ). In order to confirm this scenario and to evaluate the validity of the VCA model for $\mathrm{Ge}_{1-\mathrm{x}} \mathrm{Sn}_{\mathrm{x}}$, EXAFS signals should be collected at the Ge Kedge for the same samples to determine $\mathrm{R}_{\mathrm{GeGe}}$ and its composition dependence.

Finally, the different SRDs of the $\mathrm{Ge}_{1-\mathrm{x}} \mathrm{Sn}_{\mathrm{x}}$ layers are not reflected in the local atomic surrounding of the Sn atoms (within the accuracy of the measurements). Since the $\mathrm{Ge}_{1-\mathrm{x}} \mathrm{Sn}_{\mathrm{x}}$ layers with different $\mathrm{SRD}_{\mathrm{S}}$ exhibit different levels of compressive strain, one could expect a bimodal distribution of the Sn-Ge distances for each sample, reflecting the different values for the in-plane and out-of-plane $\mathrm{Ge}_{1-\mathrm{x}} \mathrm{Sn}_{\mathrm{x}}$ lattice constants measured by (224) RSM XRD. ${ }^{11}$ In addition, a rearrangement of the $\mathrm{Sn}-\mathrm{Ge}$ distances in a series of $\mathrm{Ge}_{1-\mathrm{x}} \mathrm{Sn}_{\mathrm{x}}$ samples with a similar concentration and different SRDs could be awaited. However, neither a bimodal distribution of the Sn-Ge distances in each sample nor the systematic rearrangement of the $\mathrm{Sn}-\mathrm{Ge}$ distances for samples with increasing SRDs were observed. This may be attributed to the fact that the discrepancies between the in-plane and outof-plane lattice constants barely range between $0.5 \%$ and $3 \%$, depending on the SRD. These discrepancies are too small to allow the discrimination of two different atomic shells in each sample, hypothetically corresponding to the in-plane and out-of-plane neighbors. In fact, the differences in the associated atomic distances $\left(\Delta_{\mathrm{d}}=\mathrm{d}_{\mathrm{SnGe} / /}-\mathrm{d}_{\mathrm{SnGe} \perp}\right)$ would be of the same order as the experimental errors of these EXAFS measurements (i.e., $0.004 \AA-0.09 \AA$, depending on the SRD). As a consequence, these two atomic shells would rather appear as a single shell at a corresponding average distance $d_{\mathrm{SnGe}}=\left(\mathrm{d}_{\mathrm{SnGe} / /}+\mathrm{d}_{\mathrm{SnGe} \perp}\right) / 2$ in the EXAFS measurements. Analogously, the expected differences between the average $\mathrm{Sn}-\mathrm{Ge}$ distances $\mathrm{d}_{\mathrm{SnGe}}$ in samples with different SRDs are also comparable to the measurement accuracy, explaining why no clear trend is observed.

\section{CONCLUSIONS}

In summary, EXAFS measurements have been used to probe the environment of $\mathrm{Sn}$ atoms in strained and relaxed $\mathrm{Ge}_{1-\mathrm{x}} \mathrm{Sn}_{\mathrm{x}}$ layers with different compositions. The preferred configuration for $\mathrm{Sn}$ incorporation in these layers is that of a $\alpha$-Sn defect, with each Sn atom covalently bonded to four Ge atoms in a tetrahedral arrangement. This EXAFS analysis indicates that the investigated materials are homogeneous random substitutional alloys. Sn interstitials, SV complexes, or Sn dimers or clusters, if present at all, are not expected to involve more than $2.5 \%$ of the total $\mathrm{Sn}$ atoms (i.e., $\sim 1 \times$ $10^{20}$ defects $\mathrm{cm}^{-3}$ ). This is advantageous for both electrical and optical applications. For instance, these defects could (i) reduce the carrier mobility in the $\mathrm{Ge}_{1-\mathrm{x}} \mathrm{Sn}_{\mathrm{x}}$ layers and increase their contact resistance, (ii) compromise their effectiveness as stressors, or (iii) increase the minimum Sn concentration required to obtain direct bandgap materials. ${ }^{9}$ These EXAFS results can be useful to develop more accurate VCA-based or atomistic models of $\mathrm{Ge}_{1-\mathrm{x}} \mathrm{Sn}_{\mathrm{x}}$ by including an experimentally verified description of the local surrounding of the Sn atoms. Within the accuracy of these measurements, the different SRDs of the examined layers are not reflected in the local atomic surrounding of the $\mathrm{Sn}$ atoms. The calculated topological rigidity parameter $\mathrm{a}^{* *}=0.69$ \pm 0.29 indicates that the alloying-induced strain in $\mathrm{Ge}_{1-\mathrm{x}} \mathrm{Sn}_{\mathrm{x}}$ is accommodated via bond stretching and bond bending, with a slight predominance of the latter, in agreement with ab initio calculations reported in literature. ${ }^{32}$ This predominantly Pauling-type behavior allows the confinement of most of the bond distortion in the first atomic shell around the Sn atoms. This study suggests that the Ge-Ge, the Ge-Sn, and the $\mathrm{Sn}-\mathrm{Sn}$ bond lengths have a similar composition dependence. In order to confirm this hypothesis and to address the validity of the VCA model for $\mathrm{Ge}_{1-\mathrm{x}} \mathrm{Sn}_{\mathrm{x}}$, EXAFS signals should be collected at the Ge K-edge for the same samples to determine $\mathrm{R}_{\mathrm{GeGe}}$ and its composition dependence. Complementary measurements are also needed to explain the low coordination numbers observed in these $\mathrm{Ge}_{1-\mathrm{x}} \mathrm{Sn}_{\mathrm{x}}$ layers and, possibly, to detect specific Sn-vacancies configurations or low concentrations of Sn interstitials or dimers.

\section{ACKNOWLEDGMENTS}

Access to the ESRF (DUBBLE-experiment 26-01-954) was arranged through the general support of the Fund for Scientific Research-Flanders (FWO) for the use of central facilities. We are grateful to the local contact at ESRF, Dr. Sergey Nikitenko, for providing assistance in using the DUBBLE beamline. We acknowledge the KU Leuven Concerted Action Program (GOA/14/007). We would like to thank Voltaix and Dow for providing $\mathrm{Ge}_{2} \mathrm{H}_{6}$ and $\mathrm{SnCl}_{4}$, respectively. We also thank the imec core partners within the imec's Industrial Affiliation Program on Logic and OIO. Finally, parts of this work frame within a collaboration funded by the Fund for Scientific Research-Flanders (FWO) and the Japan Society for the Promotion of Science with Project No. VS.018.10N.

${ }^{1}$ J. Taraci, S. Zollner, M. R. McCartney, J. Menendez, D. J. Smith, J. Tolle, M. Bauer, E. D. N. V. Edwards, and J. Kouvetakis, Optical Vibrational and Structural Properties of $G e_{1-x} S n_{x}$ Alloys by UHV-CVD (Mater. Res. Soc. Symp. Proc., 2002), Vol. 692, p. 631.

${ }^{2}$ B. Claflin, A. Kiefer, R. Beeler, Z. Q. Fang, and G. Grzybowski, "Characterization of $\mathrm{Ge}_{1-\mathrm{x}-\mathrm{y}} \mathrm{Si}_{\mathrm{x}} \mathrm{Sn}_{\mathrm{y}}$ ternary alloys - comparison of UHVCVD and gas source MBE growth," to be presented at the ECS Fall Meeting, Cancun, Mexico, 5-10 October 2014.

${ }^{3}$ C. I. Ventura, J. D. Fuhr, and R. A. Barrio, "Nonsubstitutional single-atom defects in the $\mathrm{Ge}_{1-\mathrm{x}} \mathrm{Sn}_{\mathrm{x}}$ alloy," Phys. Rev. B 79, 155202 (2009).

${ }^{4}$ A. Chroneos, C. Jiang, R. W. Grimes, U. Schwingenschlögl, and H. Bracht, "Defect interactions in $\mathrm{Sn}_{1-\mathrm{x}} \mathrm{Ge}_{\mathrm{x}}$ random alloys," Appl. Phys. Lett. 94, 252104 (2009).

${ }^{5}$ S. Decoster, S. Cottenier, U. Wahl, J. Correia, and A. Vantomme, "Lattice location study of ion implanted Sn and Sn-related defects in Ge," Phys. Rev. B 81, 155204 (2010).

${ }^{6}$ E. Kasper, M. Kittler, M. Oehme, and T. Arguirov, "Light from germanium tin heterostructures on silicon," Proc. SPIE 8628, 86280J (2013).

${ }^{7}$ A. Mosleh, S. A. Ghetmiri, B. R. Conley, M. Hawkridge, M. Benamara,

A. Nazzal, J. Tolle, S.-Q. Yu, and H. A. Naseem, "Material 
characterization of $\mathrm{Ge}_{1-\mathrm{x}} \mathrm{Sn}_{\mathrm{x}}$ alloys grown by a commercial CVD system for optoelectronic device applications," J. Electron. Mater. 43, 938 (2014). ${ }^{8}$ V. P. Markevich, A. R. Peaker, B. Hamilton, V. V. Litvinov, Y. M. Pokotilo, S. B. Lastovskii, J. Coutinho, A. Carvalho, M. J. Rayson, and P. R. Briddon, "Tin-vacancy complex in germanium,” J. Appl. Phys. 109, 083705 (2011).

${ }^{9}$ R. A. Barrio, J. D. Q. Flores, J. D. Fuhr, and C. I. Ventura, "Non-substitutional Sn defects in GeSn alloys for opto- and nanoelectronics," J. Supercond. Novel Magn. 26, 2213 (2013).

${ }^{10}$ M. Jaros, "Electronic properties of semiconductor alloy systems," Rep. Prog. Phys. 48, 1091 (1985).

${ }^{11}$ F. Gencarelli, B. Vincent, J. Demeulemeester, A. Vantomme, A. Moussa, A. Franquet, A. Kumar, H. Bender, J. Meersschaut, W. Vandervorst, R. Loo, M. Caymax, K. Temst, and M. Heyns, "Crystalline properties and strain relaxation mechanism of CVD grown GeSn," ECS J. Solid State Sci. Technol. 2, P134 (2013).

${ }^{12}$ D. Koningsberger, B. Mojet, G. van Dorssen, and D. Ramaker, "XAFS spectroscopy; fundamental principle and data analysis," Top. Catal. 10, 143 (2000).

${ }^{13}$ R. Loo, G. Wang, L. Souriau, J. C. Lin, S. Takeuchi, G. Brammertz, and M. Caymax, "High quality Ge virtual substrates on $\mathrm{Si}$ wafers with standard STI patterning," J. Electrochem. Soc. 157, H13 (2010).

${ }^{14}$ F. Gencarelli, B. Vincent, L. Souriau, O. Richard, W. Vandervorst, R. Loo, M. Caymax, and M. Heyns, "Low-temperature Ge and GeSn chemical vapor deposition using $\mathrm{Ge}_{2} \mathrm{H}_{6}$," Thin Solid Films 520, 3211 (2012).

${ }^{15}$ M. Borsboom, W. Bras, I. Cerjak, D. Detollenaere, D. G. van Loon, P. Goedtkindt, M. Konijnenburg, P. Lassing, Y. K. Levine, B. Munneke, M. Oversluizen, R. van Tol, and E. Vlieg, "The Dutch-Belgian beamline at the ESRF," J. Synchrotron Radiat. 5, 518 (1998).

${ }^{16}$ N. Binsted, J. W. Campbell, S. J. Gurman, and P. C. Stephenson, EXAFS Analysis Programs, Daresbury Laboratory, Warrington, UK, 1991.

${ }^{17} \mathrm{M}$. Newville, Fundamentals of XAFS, Consortium for Advanced Radiation Sources (University of Chicago, 2004), p. 41.

${ }^{18}$ L. Hedin and B. I. Lundqvist, "Explicit local exchange-correlation potentials," J. Phys. C 4, 2064 (1971).

${ }^{19}$ D. Grandjean, R. E. Benfield, C. Nayral, A. Maisonnat, and B. Chaudret, "EXAFS and XANES study of a pure and Pd doped novel Sn/SnOx nanomaterial," J. Phys. Chem. B 108, 8876 (2004).

${ }^{20} \mathrm{~L}$. Pauling, The Nature of the Chemical Bond (Cornell University Press, Ithaca, New York, 1960).

${ }^{21}$ P. F. Lang and B. C. Smith, "An equation to calculate internuclear distances of covalent, ionic and metallic lattices," Phys. Chem. Chem. Phys. 17, 3355 (2015).

${ }^{22}$ P. F. Lang and B. C. Smith, "Electronegativity effects and single covalent bond lengths of molecules in the gas phase," Dalton Trans. 43, 8016 (2014).

${ }^{23}$ T. Philippe, F. D. Geuser, S. Duguay, W. Lefebvre, O. Cojocaru-Mirédin, G. D. Costa, and D. Blavette, "Clustering and nearest neighbour distances in atom-probe tomography," Ultramicroscopy 109, 1304 (2009).

${ }^{24}$ J. D. Fuhr, C. I. Ventura, and R. A. Barrio, "Formation of nonsubstitutional $\beta$-Sn defects in $\mathrm{Ge}_{1-\mathrm{x}} \mathrm{Sn}_{\mathrm{x}}$ alloys," J. Appl. Phys. 114, 193508 (2013).

${ }^{25}$ J. A. Lee and G. V. Raynor, "The lattice spacings of binary tin-rich alloys," Proc. Phys. Soc. London, Sect. B 67, 737 (1954).

${ }^{26}$ E. Kamiyama, K. Sueoka, O. Nakatsuka, N. Taoka, S. Zaima, K. Izunome, and K. Kashima, "Analysis for positions of $\mathrm{Sn}$ atoms in epitaxial $\mathrm{Ge}_{1}-\mathrm{xSn}_{\mathrm{x}}$ film in low temperature depositions," Thin Solid Films 557, 173 (2014).

${ }^{27}$ F. Gencarelli, Y. Shimura, A. Kumar, B. Vincent, A. Moussa, D. Vanhaeren, O. Richard, H. Bender, W. Vandervorst, M. Caymax, R. Loo, and M. Heyns, "Amorphous inclusions during Ge and GeSn CVD epitaxial growth," Thin Solid Films (submitted).

${ }^{28}$ Y. Cai and M. F. Thorpe, "Length mismatch in random semiconductor alloys. I. General theory for quaternaries,” Phys. Rev. B 46, 15872 (1992).

${ }^{29}$ L. Vegard, "Die Konstitution der Mischkristalle und die Raumfüllung der Atome," Z. Phys. 5, 17 (1921).

${ }^{30} \mathrm{~L}$. Pauling, The Nature of the Chemical Bond (Cornell University Press, Ithaca, NY, 1967).
${ }^{31}$ P. Venezuela, G. M. Dalpian, A. J. R. da Silva, and A. Fazzio, “Ab initio determination of the atomistic structure of $\mathrm{Si}_{\mathrm{x}} \mathrm{Ge}_{1-\mathrm{x}}$ alloy," Phys. Rev. B 64, 193202 (2001)

${ }^{32}$ J. Shen, J. Zi, X. Xie, and P. Jiang, "Ab initio calculation of the structure of the random alloys $\mathrm{Sn}_{\mathrm{x}} \mathrm{Ge}_{1-\mathrm{x}}$," Phys. Rev. B 56, 12084 (1997).

${ }^{33}$ R. H. Parmenter, "Energy levels of a disordered alloy," Phys. Rev. 97, 587 (1955).

${ }^{34}$ D. B. Aldrich, R. J. Nemanich, and D. E. Sayers, "Bond length relaxation in $\mathrm{Si}_{-x} \mathrm{Ge}_{\mathrm{x}}$ alloys," Phys. Rev. B 50, 15026 (1994).

${ }^{35} \mathrm{H}$. Rucker and M. Methfessel, "Anharmonic Keating model for group-IV semiconductors with application to the lattice dynamics in alloys of $\mathrm{Si}$, Ge, and C," Phys. Rev. B 52, 11059 (1995).

${ }^{36} \mathrm{~J}$. C. Mikkelsen, Jr. and J. B. Boyce, "Extended x-ray-absorption finestructure study of $\mathrm{Ga}_{1-\mathrm{x}} \mathrm{In}_{\mathrm{x}}$ As random solid solutions," Phys. Rev. B 28, 7130 (1983)

${ }^{37} \mathrm{G}$. He and $\mathrm{H}$. A. Atwater, "Interband transitions in $\mathrm{Sn}_{\mathrm{x}} \mathrm{Ge}_{1-\mathrm{x}}$ alloys," Phys. Rev. Lett. 79, 1937 (1997).

${ }^{38}$ V. R. D'Costa, C. S. Cook, A. G. Birdwell, C. L. Littler, M. Canonico, S. Zollner, J. Kouvetakis, and J. Menendez, "Optical critical points of thinfilm $\mathrm{Ge}_{1-\mathrm{y}} \mathrm{Sn}_{\mathrm{y}}$ alloys: a comparative $\mathrm{Ge}_{1-\mathrm{y}} \mathrm{Sn}_{\mathrm{y}}-\mathrm{Ge}_{1-\mathrm{x}} \mathrm{Si}_{\mathrm{x}}$ study, Phys. Rev. B 73, 125207 (2006)

${ }^{39} \mathrm{P}$. Moontragoon, Z. Ikonic, and P. Harrison, "Band structure calculations of Si-Ge-Sn alloys: Achieving direct band gap materials," Semicond. Sci. Technol. 22, 742 (2007).

${ }^{40}$ S. Shimura, Y. Wang, W. Nieddu, T. Gencarelli, F. Vincent, B. Laha, P. Terryn, H. Stefanov, S. S. Chiussi, J. V. Campenhout, N. D. Nguyen, A. Vantomme, and R. Loo, "Bandgap measurement by spectroscopic ellipsometry for strained $\mathrm{Ge}_{1-x} \mathrm{Sn}_{\mathrm{x}}$," in the 8th International Conference on Silicon Epitaxy and Heterostructures (ICSI-8), Fukuoka, Japan, 2013.

${ }^{41}$ S. Gupta, B. Magyari-Kope, Y. Nishi, and K. C. Saraswat, "Achieving direct band gap in germanium through integration of Sn alloying and external strain,” J. Appl. Phys. 113, 073707 (2013).

${ }^{42}$ D. Stroud and H. Ehrenreich, "Band structure of SiGe: Coherent-potential approximation," Phys. Rev. B 2, 3197 (1970).

${ }^{43}$ K. E. Newman and J. D. Dow, "Theory of deep impurities in silicongermanium alloys," Phys. Rev. B 30, 1929 (1984).

${ }^{44}$ J. C. Aubry, T. Tyliszczak, A. P. Hitchcock, J.-M. Baribeau, and T. E. Jackman, "First shell bond lengths in $\mathrm{Si}_{\mathrm{x}} \mathrm{Ge}_{1-\mathrm{x}}$ single crystal alloys," Phys. Rev. B 59, 12872 (1999).

${ }^{45}$ I. Yonenaga, M. Sakurai, and M. H. F. Sluiter, "Growth and atomistic structure study of disordered SiGe mixed semiconductors," Mater. Sci. Forum 539-543, 2043 (2007)

${ }^{46}$ C. Maurizio, G. Mattei, P. Mazzoldi, S. Padovani, E. Cattaruzza, F. Gonella, F. Dacapito, and F. Zontone, "Deviation from the virtual crystal approximation in disordered $\mathrm{Au}-\mathrm{Cu}$ alloy nanocrystals: EXAFS and GIXRD investigation,” Nucl. Instrum. Methods Phys. Res., Sect. B 200, 178 (2003).

${ }^{47}$ Y. Chibane, B. Bouhafs, and M. Ferhat, "Unusual structural and electronic properties of $\mathrm{Sn}_{\mathrm{x}} \mathrm{Ge}_{1-\mathrm{x}}$ alloys," Phys. Status Solidi B 240, 116 (2003).

${ }^{48}$ H. P. L. de Guevara, A. G. Rodríguez, H. Navarro-Contreras, and M. A. Vidal, "Nonlinear behavior of the energy gap in $\mathrm{Ge}_{1-\mathrm{x}} \mathrm{Sn}_{\mathrm{x}}$ alloys at $4 \mathrm{~K}$," Appl. Phys. Lett. 91, 161909 (2007).

${ }^{49}$ B. Bouhafs, F. Benkabou, M. Ferhat, B. Khelifa, J. P. Dufour, and H. Aourag, "Energy band structure calculation of $\mathrm{Ge}_{x} \mathrm{Sn}_{1-\mathrm{x}}$ and $\mathrm{Si}_{\mathrm{x}} \mathrm{Sn}_{1-\mathrm{x}}$ alloys," Infrared Phys. Technol. 36, 967 (1995).

${ }^{50} \mathrm{~N}$. Bouarissa and F. Annane, "Electronic properties and elastic constants of the ordered $\mathrm{Ge}_{1-\mathrm{x}} \mathrm{Sn}_{\mathrm{x}}$ alloys," Mater. Sci. Eng., B 95, 100 (2002).

${ }^{51} \mathrm{Y}$. Chibane and M. Ferhat, "Electronic structure of $\mathrm{Sn}_{\mathrm{x}} \mathrm{Ge}_{1-\mathrm{x}}$ alloys for small Sn compositions: Unusual structural and electronic properties," J. Appl. Phys. 107, 053512 (2010).

${ }^{52}$ M. Matsuura, J. M. Tonnerre, and G. S. Cargill, "Lattice parameters and local atomic structure of silicon-rich Si-Ge/Si (100) films," Phys. Rev. B 44, $3842(1991)$

${ }^{53}$ M. C. Ridgway, K. M. Yu, C. J. Glover, G. J. Foran, C. Clerc, J. L. Hansen, and A. N. Larsen, "Composition-dependent bond lengths in crystalline and amorphized $\mathrm{Ge}_{x} \mathrm{Si}_{1-\mathrm{x}}$ alloys," Phys. Rev. B 60, 10831 (1999). 